\title{
REFLEXIONES EN TORNO AL MARCO NORMATIVO EN MATERIA DE INVESTIGACIONES QUE IMPLICAN PROCEDIMIENTOS INVASIVOS EN SERES HUMANOS EN ESPAÑA
}

\author{
Asier Urruela Mora \\ Profesor Titular de Derecho Penal (Universidad de Zaragoza) \\ Asesor Cátedra Interuniversitaria de Derecho y Genoma Humano (Diputación Foral de \\ Bizkaia/Universidad del País Vasco-EHU/Universidad de Deusto)
}

Sumario. 1. Consideraciones generales y ubicación sistemática. 2. Antecedentes históricos. 2.1. Código de Nüremberg. 2.2. Declaración de Helsinki. 2.3. Informe Belmont. 2.4. La Declaración Universal sobre Bioética y Derechos Humanos de la UNESCO (19 octubre de 2005). 2.5. Documentos del Consejo de Organizaciones Internacionales de las Ciencias Médicas (CIOMS), de la Organización Mundial de la Salud (OMS) y de la Conferencia Internacional sobre Armonización de los Requerimientos Técnicos para el Registro de Fármacos de Uso Humano (ICH). 2.6. Normativa comunitaria y española sobre ensayos clínicos con medicamentos de uso humano y productos sanitarios. 3. El antecedente inmediato: La Convención del Consejo de Europa sobre los Derechos del Hombre y la Biomedicina y su Protocolo Adicional relativo a la investigación biomédica de 25.1.2005. 3.1. La Convención del Consejo de Europa sobre los Derechos del Hombre y la Biomedicina. 3.2. Protocolo Adicional al Convenio sobre Derechos Humanos y la Biomedicina, relativo a la Investigación Biomédica. 4. Análisis de la Ley de Investigación Biomédica. 4.1. Visión de conjunto del Título II. 4.2. Ámbito de aplicación del Título II Ley de Investigación Biomédica. 4.3. Capítulo I. Principios generales y requisitos de la información y consentimiento. 4.4. Capítulo II. Evaluación, autorización y aseguramiento del daño. 4.5. Capítulo III. Situaciones específicas. 4.6. Capítulo IV. Seguridad y supervisión. 4.7. Capítulo V. Gestión de la información.

\section{CONSIDERACIONES GENERALES Y UBICACIÓN SISTEMÁTICA.}

El Título II de la Ley 14/2007, de 3 de julio, de Investigación Biomédica ${ }^{1}$ lleva por rúbrica «Investigaciones que implican procedimientos invasivos en seres humanos», abarcando, a lo largo de sus cinco capítulos, los arts. 13 a 27 ambos inclusive. A través del conjunto de preceptos referidos se pretende establecer una caracterización general de las reglas a las que quedan sometidas las experimentaciones en las que participan directamente personas (excluyendo las meramente observacionales), si bien cuando las mismas se

${ }^{1}$ Ley 14/2007, de 3 de julio, de Investigación Biomédica. Boletín Oficial del Estado, 4 de julio de 2007, núm. 159. 
vinculan al ámbito de los medicamentos y productos sanitarios, son objeto de una regulación específica en virtud de la normativa sectorial.

En este sentido, procede poner de manifiesto que si bien la experimentación con seres humanos existe desde antiguo, si entendemos la misma como práctica científica dirigida a comprobar en individuos determinadas hipótesis capaces de producir avances en la esfera de la medicina, se trata de un fenómeno relativamente reciente que cabría situar en el siglo XIX ${ }^{2}$. Hito esencial en este proceso lo constituyó la publicación en 1865 de la obra de Claude Bernard Introducción al estudio de la medicina experimental, momento a partir del cual la experimentación adquiere carta de naturaleza, quedando fijados los principios de una verdadera metodología científica para la medicina ${ }^{3}$.

A partir de este hito, la investigación biomédica se ha desarrollado de una manera constante, quedando expuesta, no obstante, a importantes excesos, siendo los más conocidos los experimentos con seres humanos desarrollados por científicos durante el régimen nacionalsocialista alemán que han pasado desgraciadamente a los anales de la historia como los mayores ejemplos de tortura y sufrimiento inflingidos a personas vivas. No obstante, la existencia de abusos intolerables en el curso de investigaciones no ha constituido característica exclusiva de los regímenes totalitarios, sino que se ha producido lamentablemente con excesiva frecuencia también en estados democráti$\cos ^{4}$. Ante tan dramáticas experiencias, a lo largo del siglo XX, particular-

${ }^{2}$ Así lo pone de manifiesto GonzÁlez-Torre, A. P., Bioética y experimentación con seres humanos, Comares, Granada, 2002, p. 1.

3 Ibidem, pp. 2 y ss.

${ }^{4}$ Uno de los episodios más tristes de este proceso investigador en seres humanos a lo largo del siglo XX lo constituye, sin lugar a dudas, el estudio Tuskegee sobre sífilis, desarrollado entre 1932 y 1972 por el Servicio de Salud Pública norteamericano. En el curso del mismo, seiscientos afroamericanos de baja extracción social, cuatrocientos de los cuales se encontraban infectados de sífilis, fueron objeto de monitorización durante cuarenta años. A pesar de ser sometidos a exámenes médicos continuados no se les comunicó a los individuos su enfermedad. Incluso aunque en la década de los cincuenta se conoció la existencia de un método curativo de eficacia probada (penicilina), el estudio se prolongó hasta 1972 siéndoles denegado a los participantes el tratamiento. Llegaron a conocerse casos en los que, estando la sífilis diagnosticada por otros médicos, investigadores intervinieron con el fin de evitar que se suministrase a los participantes tratamiento alguno. En este contexto, numerosos sujetos murieron de sífilis durante el estudio. La investigación fue interrumpida en 1973 por el Departamento de Salud, Educación y Bienestar norteamericano únicamente cuando su existencia fue publicitada y se convirtió en un problema desde el punto de vista político. En 1997, y bajo una presión pública creciente, el Presidente Clinton pidió disculpas a los participantes y a sus familias. Véase Division Of Research And Graduate Studies (Unlv)-Office For The Protection Of ReSEARCH SubJects, History of Research Ethics, [en línea], [citado el 1 de octubre de 2011], disponible en Internet: [http://research.unlv.edu/OPRS/history-ethics.htm] 
mente en su segunda mitad, se ha generado una importante reflexión ética relacionada con el desarrollo de las referidas experimentaciones en seres humanos, que se ha materializado en importantes textos de referencia (Código de Nüremberg, Declaración de Helsinki, Informe Belmont, Convenio sobre Derechos Humanos y Biomedicina del Consejo de Europa y su Protocolo adicional relativo a la Investigación Biomédica, etc.).

A lo largo del presente trabajo, se procede a analizar la normativa aplicable en España en materia de investigaciones que implican procedimientos invasivos en seres humanos de acuerdo con el Título II de la Ley de Investigación Biomédica $^{5}$, excluyendo la esfera de los ensayos clínicos ${ }^{6}$ farmacológicos y

${ }^{5}$ Huelga insistir en la importancia de la intervención del Derecho en la esfera de las experimentaciones con seres humanos, dado que en las mismas se encuentran implicados derechos constitucionalmente consagrados -algunos con el rango de derechos fundamentales-, tanto del investigador como de terceros participantes en la investigación. En este sentido, en el marco constitucional español consagran la posición del investigador el art. 20.1.b) Constitución Española -en adelante, CE- (derecho a la producción y creación literaria, artística, científica y técnica) y el art. 44.2 CE (promoción de la ciencia y de la investigación científica y técnica por parte de los poderes públicos en beneficio del interés general). Por el contrario, y dado que todo derecho (también los fundamentales) se encuentra sometido a límites en su ejercicio, deben tomarse en consideración al objeto de impedir toda ingerencia indeseada en la esfera personal de sujetos potenciales participantes en la experimentación los arts. 10.1 CE (dignidad de la persona, derechos inviolables que le son inherentes, libre desarrollo de la personalidad, respeto a la ley y a los derechos de los demás como fundamento del orden político y de la paz social), 15 $\mathrm{CE}$ (derecho de todos a la vida y a la integridad física y moral, sin que, en ningún caso, puedan ser sometidos a tortura o tratos inhumanos o degradantes), $18 \mathrm{CE}$ (derecho al honor, a la intimidad personal y familiar y a la propia imagen), 20.4 CE (fija el límite a las libertades consagradas en el art. $20 \mathrm{CE}$ en el respeto a los derechos reconocidos en el Título I Constitución, en los preceptos de las Leyes que lo desarrollan y, especialmente, en el derecho al honor, a la intimidad, a la propia imagen y a la protección de la juventud y de la infancia) y 43.1 CE (derecho a la protección de la salud). En este sentido, véase Romeo Casabona, C. M., "Aspectos jurídicos de la experimentación humana», Revista de la Facultad de Derecho de la Universidad Complutense, Monográfico 11 (Estudios de Derecho Penal en homenaje al Profesor Luis Jiménez de Asua), 1986, pp. 570 y ss.; SÁnchez CARo, J., «Protección de los sujetos participantes. Postulados éticos en la investigación con seres humanos. Ensayos con menores e incapaces», en SÁNChEZ CARO, J./ Abellán, F. (Coordinadores), Ensayos clínicos en España, Comares, Granada, 2006, pp. 76 y ss. Argumentación cercana a la de los autores anteriores desarrolla MarTín Pallín, J.A., «Barreras ético-jurídicas a la investigación clínica y farmacéutica», Jueces para la Democracia, 12, 1/1991, pp. 62 y s.

${ }^{6}$ En este sentido, siguiendo a Bonfill cabría definir los ensayos clínicos como aquellos estudios prospectivos realizados con el fin de evaluar las intervenciones que se han aplicado en más de dos grupos poblacionales creados al azar y que, por lo tanto, son comparables entre sí. Véase Bonfill, X., «Situación actual de los ensayos clínicos no farmacológicos en España», en Bonfill, X. et al., Ensayos clínicos en intervenciones no farmacológicas, Fundación Dr. Antonio Esteve-Ediciones Doyma, Barcelona, 2001, p. 1. 
vinculados con los productos sanitarios que cuentan con su propia regulación específica. Para ello procederemos, en un primer momento, a realizar un repaso histórico de los distintos textos internacionales de referencia dirigidos a abordar el tema de la experimentación humana desde una perspectiva ética. Posteriormente, y ya desde un prisma eminentemente jurídico, abordaremos la normativa concurrente en el Título II de la Ley de Investigación Biomédica respecto de la cual resulta ineludible citar -por constituir el referente inmediato de la misma- tanto el Convenio para la protección de los Derechos Humanos y la Dignidad del ser humano con respecto a las aplicaciones de la Biología y la Medicina (en adelante, Convenio relativo a los Derechos Humanos y la Biomedicina o Convenio de Oviedo) de 4 de abril de 1997, que en su capítulo $\mathrm{V}$ regula la materia relativa a la experimentación científica, como su Protocolo Adicional relativo a la Investigación Biomédica (2005) ${ }^{7}$.

\section{ANTECEDENTES HISTÓRICOS.}

El origen de la regulación contenida en la Ley de Investigación Biomédica en relación con la materia estudiada hay que situarlo en la esfera internacional. Desde un punto de vista material han incidido en estas esferas el Código de Nüremberg, la Declaración de Helsinki de la Asociación Médica Mundial, el informe Belmont, y de manera directa, como se puso de manifiesto anteriormente, el Convenio relativo a los Derechos Humanos y la Biomedicina del Consejo de Europa en el marco del cual se ha aprobado un Protocolo Adicional relativo a la Investigación Biomédica.

\subsection{Código de Nüremberg.}

En primer lugar, y con carácter histórico, cabría afirmar que los diez principios de Nüremberg, establecidos por el Tribunal Internacional Militar que procedió al enjuiciamiento de médicos e investigadores responsables de

${ }^{7}$ En relación con el particular, como pone de manifiesto GONZÁLEZ-Torre, si bien «es cierto que la legislación por sí sola no podrá alcanzar a «supervisar» las probetas de los laboratorios (de hecho son escasísimos los supuestos que llegan a los tribunales, y sería absurdo pensar en una judicialización de la actividad científica), y que lo fundamental es cultivar la ética del investigador, (...) esto no implica que la legislación deba quedar al margen. La misión de la ley es por un lado configurar un modelo de comportamiento para los científicos, cuyos principios se inspiren en las necesidades sociales comúnmente admitidas, o al menos mayoritariamente acordadas, y por otro evitar en la medida de lo posible que el desarrollo científico vulnere intereses públicos o derechos privados jurídicamente protegidos. La autonomía de la ciencia, el valor intrínseco del progreso científico, no son ya consideraciones que justifiquen un actuar al margen de un derecho que debe funcionar como manifestación y garantía de los intereses generales y de los derechos de los individuos». Véase GonzÁlez-Torre, A. P., «Investigación científica (Capítulo V)», en Romeo Casabona, C. M. (editor), El Convenio de Derechos Humanos y Biomedicina, Cátedra de Derecho y Genoma Humano-Editorial Comares, Bilbao-Granada, 2002, pp. 240 y ss. 
experimentos llevados a cabo con prisioneros en campos de concentración, vendría a constituir la primera normativa internacional ${ }^{8}$ en este ámbito ${ }^{9}$. En concreto, los preceptos que configuraban el conocido como Código de Nüremberg $^{10}$ son los siguientes:

1. Es absolutamente esencial el consentimiento voluntario del sujeto humano.

Esto significa que la persona implicada debe tener capacidad legal para otorgar su consentimiento; su situación debe ser tal que pueda ser capaz de ejercer una elección libre, sin intervención de cualquier elemento de fuerza, fraude, engaño, coacción u otra forma de constreñimiento o coerción; debe tener suficiente conocimiento y comprensión de los elementos implicados que le capaciten para adoptar una decisión razonable e ilustrada. Este último elemento requiere que antes de que se acepte una decisión afirmativa por parte del sujeto de la experimentación debe conocer la naturaleza, duración y fines del experimento, el método y los medios con los que será realizado; todos los inconvenientes y riesgos que pueden ser esperados razonablemente y los efectos sobre su salud y persona que pueden posiblemente originarse de su participación en el experimento.

El deber y la responsabilidad para asegurarse de la calidad del consentimiento residen en cada individuo que inicie, dirija o esté implicado en el experimento. Es un deber y responsabilidad personales que no pueden ser delegados impunemente.

2. El experimento debe ser tal que produzca resultados provechosos para el beneficio de la sociedad, no obtenibles por otros métodos o medios y no de naturaleza aleatoria o innecesaria.

3. El experimento debe ser proyectado y basado en los resultados de la experimentación animal y en un conocimiento de la historia natural de la

${ }^{8}$ A nivel nacional alemán Deutsch establece que la primera directiva conocida data de 1900 y fue promulgada por el ministro de cultura de Prusia en reacción a las denuncias aparecidas en la prensa popular con motivo de los ensayos clínicos que se llevaban a cabo en la Universidad de Greifswald, que implicó un número importante de víctimas. La normativa en cuestión exigía la aprobación del protocolo experimental por parte del jefe del servicio, no permitía experimentar en niños o disminuidos psíquicos y los pacientes debían otorgar su consentimiento previo. Véase Deutsch, E., «La declaración de Helsinki y la Convención Europea de Bioética. Problemas asociados a la regulación de la experimentación médica», en Palacios, M. (coordinador), Bioética 2000, Ediciones Nobel, Oviedo, 2003, pp. 183 y s.

9 Véase SÁnchez Caro, J., «Protección de los sujetos participantes. Postulados éticos en la investigación con seres humanos. Ensayos con menores e incapaces», cit., p. 56; Deutsch, E., «La declaración de Helsinki y la Convención Europea de Bioética. Problemas asociados a la regulación de la experimentación médica», cit., p. 184.

${ }_{10}$ Procederemos a reproducir íntegramente dichos principios a partir de la traducción de los mismos realizada por el Observatori de Bioética i Dret. Véase Código de Nüremberg, [en línea], 1947 [citado el 1 de octubre de 2011], disponible en Internet: [http:// www.pcb.ub.es/bioeticaidret/archivos/norm/CodigoNuremberg.pdf] 
enfermedad o de otro problema objeto de estudio, de tal forma que los resultados previos justificarán la realización del experimento.

4. El experimento debe ser realizado de tal forma que se evite todo sufrimiento físico y mental innecesario y todo daño.

5. No debe realizarse ningún experimento cuando exista una razón a priori que lleve a creer que pueda sobrevenir muerte o daño incapacitante, excepto, quizás, en aquellos experimentos en que los médicos investigadores participen también como sujetos.

6. El grado de riesgo que ha de ser tomado no debe exceder nunca el determinado por la importancia humanitaria del problema que ha de ser resuelto con el experimento.

7. Deben llevarse a cabo los preparativos apropiados y proveerse de las infraestructuras adecuadas para proteger al sujeto de la experimentación contra posibilidades, incluso remotas, de daño, incapacitación o muerte.

8. El experimento debe ser realizado únicamente por personas científicamente cualificadas. Debe exigirse a lo largo de todas las etapas del experimento el mayor grado de pericia y cuidado en aquellos que realizan o están implicados en dicho experimento.

9. Durante el curso del experimento el sujeto humano debe ser libre de interrumpirlo si se encuentra en un estado físico o mental en el que la continuación del experimento le parezca imposible.

10. Durante el curso del experimento el científico responsable tiene que estar preparado para terminarlo en cualquier fase, si tiene una razón para creer con toda probabilidad, en el ejercicio de la buena fe, superior destreza y juicio cuidadoso que se requiere de él, que la continuación del experimento traerá probablemente como resultado daño, discapacidad o muerte del sujeto de la experimentación.

Los criterios configurados en el conocido Código de Nüremberg no conservan en su totalidad plena vigencia actual (así la proscripción absoluta de investigar con incapaces, lo cual daría lugar al bloqueo de facto de la actividad experimental -y, por lo tanto, del desarrollo de nuevas terapias- en este ámbito) pero constituyen un antecedente histórico y un referente válido de la actividad normativa producida posteriormente en esta materia tanto a nivel internacional como comparado. Incluso alguno de ellos puede estimarse, bajo nuestra conciencia ética actual absolutamente censurable, como el que permitiría la asunción de riesgos extraordinarios (muerte o daños incapacitantes graves) en la medida en que el investigador participe igualmente como sujeto del estudio. Por otro lado, el Código de Nüremberg no establecía diferenciación alguna entre investigación científica y terapéutica ${ }^{11}$.

${ }^{11}$ En este sentido, Véase SÁnchez CARo, J., «Protección de los sujetos participantes. Postulados éticos en la investigación con seres humanos. Ensayos con menores e incapaces», cit., p. 57. 
Sánchez Caro $^{12}$ reconduce los principios de Nüremberg en materia de experimentación con seres humanos a tres criterios básicos: consentimiento del sujeto como elemento esencial, protección de los sujetos incluidos en el ensayo y primacía del sujeto sobre el interés de la ciencia. De esta manera, el Código de Nüremberg de 1947 se erige en el primer documento internacional sobre ética de la investigación, estableciendo el inicio de una particular preocupación por la actividad experimental humana, inspirando las posteriores reglamentaciones ${ }^{13}$.

\subsection{Declaración de Helsinki.}

En el marco del proceso histórico de configuración de códigos éticos supranacionales en materia de investigación y experimentación con seres humanos, procede destacar igualmente la importancia que en el desarrollo de una armonización normativa ostenta la Declaración de Helsinki ${ }^{14}$, adoptada por la $18^{\mathrm{a}}$ Asamblea de la Asociación Médica Mundial (1964) y objeto de enmiendas sucesivas en la 29a Asamblea Médica Mundial celebrada en Tokio (1975), en la 35 a Asamblea Médica Mundial de Venecia (1983), en la $41^{\text {a }}$ Asamblea Médica Mundial de Hong Kong (1989), en la $48^{\mathrm{a}}$ Asamblea General en Sommerset West (Sudáfrica) (1996), en la 52 Asamblea General reunida en Edimburgo (2000) y en la 59 Asamblea General reunida en Seúl (Corea) (2008).

Su estructura se compone de una introducción y dos apartados (B. Principios Básicos para toda investigación médica; C. Principios aplicables cuando la investigación médica se combina con la atención médica), y a partir de su elaboración se ha convertido en referente absoluto en materia de investigación biomédica a nivel internacional.

Desde un punto de vista material, la Declaración de Helsinki establece una serie de criterios que se han consolidado y que aún hoy mantienen plena vigencia en la praxis comparada. En su introducción la Declaración de Helsinki se configura como una propuesta de principios éticos destinada a orientar a los médicos y a otras personas que lleven a cabo investigación en seres

12 Véase Sánchez Caro, J., «Protección de los sujetos participantes. Postulados éticos en la investigación con seres humanos. Ensayos con menores e incapaces», cit., pp. 57 y s.

13 Tal como ponen de manifiesto Vega Gutiérrez, J. / Vega Gutiérrez, J.M./Martínez BAzA, P., Experimentación humana en Europa, Universidad de Valladolid, Valladolid, 1997, pp. 44 y ss. Particular importancia ostenta en este sentido el art. 7 del Pacto Internacional de Derechos Civiles y Políticos (1966) que dispone «nadie será sometido a torturas ni a penas o tratos crueles, inhumanos o degradantes. En particular, nadie será sometido sin su libre consentimiento a experimentos médicos o científicos»».

14 Texto íntegro vigente de la declaración en Asociación Médica Mundial, Declaración de Helsinki de la Asociación Médica Mundial. Principios éticos para las investigaciones médicas en seres humanos, [en línea], 2008 [citado el 1 de octubre de 2011], disponible en Internet: [http://www.wma.net/en/30publications/10policies/b3/index.html] 
humanos. Se parte, por otro lado, del reconocimiento de que el progreso de la medicina se basa en la investigación, que, en muchas ocasiones, exige recurrir en último término a la experimentación con seres humanos. Además, se establece de manera expresa un principio que ha adquirido rango fundamental en la esfera de la bioética, como es el de que (en investigación médica en seres humanos) el bienestar de las personas debe tener siempre primacía sobre los restantes intereses (particularmente los de la ciencia y de la sociedad).

En el ámbito de los principios básicos para toda investigación médica se requiere que la experimentación en seres humanos se conforme con base en los principios éticos generalmente aceptados y se apoye en un profundo conocimiento de la bibliografía científica y en otras fuentes de información disponibles, así como en experimentos de laboratorio y en animales, cuando resulte oportuno. El desarrollo de una conciencia medioambiental a nivel internacional queda de manifiesto en la exigencia de que la experimentación tome en consideración su impacto sobre el medio ambiente, debiéndose prestar el cuidado debido con el fin de garantizar el bienestar de los animales utilizados en los experimentos. El apartado 14 ostenta una importancia fundamental pues implica la exigencia de que el proyecto y el método de todo estudio en seres humanos se describan claramente en un protocolo de investigación que debe hacer referencia a las consideraciones éticas atinentes al caso e indicar cómo se han considerado los principios enunciados en la Declaración. Asimismo debe incluir información sobre financiación, patrocinadores, afiliaciones institucionales, otros posibles conflictos de interés e incentivos para los sujetos participantes en el estudio y sobre las estipulaciones para tratar o compensar a las personas que han sufrido daños como consecuencia de su participación en la investigación. Finalmente, el mencionado documento debe describir los mecanismos para el acceso después del ensayo a intervenciones identificadas como beneficiosas en el estudio o el acceso a otra atención o beneficios apropiados. El protocolo ha de remitirse antes de comenzar el estudio, a efectos de su toma en consideración, comentario, consejo y aprobación, a un comité de evaluación ética independiente del investigador, patrocinador o de cualquier otro tipo de influencia indebida. Dicho comité ostenta el derecho a controlar los ensayos en curso, debiendo el investigador proporcionar información del control al comité, en especial sobre todo incidente adverso grave.

Por otro lado, la investigación médica en seres humanos debe ser llevada a cabo sólo por personas con la formación y calificación científicas apropiadas, requiriendo la investigación en pacientes o voluntarios sanos de la supervisión de un médico u otro profesional de la salud competente y calificado apropiadamente. La responsabilidad de la protección de las personas que toman parte en la investigación debe recaer siempre en un médico u otro profesional de la salud y nunca en los participantes de la investigación. 
La Declaración de Helsinki exige específicamente que toda investigación médica en seres humanos sea precedida de una cuidadosa comparación de los riesgos y los costos para las personas y las comunidades que participan en la investigación, en comparación con los beneficios previsibles para ellos y para otras personas o comunidades afectadas por la enfermedad que se investiga. En este sentido, los médicos no deben participar en estudios de investigación en seres humanos a menos de que estén seguros de que los riesgos inherentes han sido adecuadamente evaluados y de que es posible hacerles frente de manera satisfactoria. Por otro lado, en el curso de las investigaciones médicas deben tomarse toda clase de precauciones para resguardar la intimidad de las personas que participan en las mismas y la confidencialidad de su información personal y para reducir al mínimo las consecuencias de la investigación sobre su integridad física, mental y social.

Partiendo del dato de que la participación de personas competentes en una investigación médica ha de ser voluntaria, un ulterior aspecto que procede destacar adecuadamente es el relativo al consentimiento informado, que debe obtenerse preferentemente por escrito -en cuyo defecto deberá ser documentado y atestiguado formalmente-, exigiéndose en materia de información un nivel adecuado a suministrar a los sujetos implicados (incluyendo los objetivos, métodos, fuentes de financiación, posibles conflictos de intereses, afiliaciones institucionales del investigador, beneficios calculados, riesgos previsibles e incomodidades derivadas del experimento, así como el derecho a participar o no y a retirar el consentimiento en cualquier momento).

En relación con los supuestos de incapacidad, la declaración dispone que cuando el individuo potencial sea incapaz, el investigador debe obtener el consentimiento informado del representante legal. No obstante, en el caso en el que una persona considerada incompetente por la ley, como es el caso de un menor de edad, sea capaz de asentir o rechazar su participación en la experimentación, el investigador debe obtener dicha conformidad, además del consentimiento del representante legal, debiéndose respetar el desacuerdo del individuo potencial. De cualquier manera, las personas incapaces no deben ser incluidas en una investigación que no presente posibilidades de beneficio para ellas, a menos que ésta tenga como objetivo promover la salud de la población representada por el individuo potencial y esta investigación no pueda realizarse en personas competentes e implique sólo un riesgo y costo mínimos. Por otro lado, se dispone que la experimentación en individuos que no son capaces física o mentalmente de otorgar consentimiento (así, pacientes inconscientes) se puede realizar sólo si la condición física o mental que impide otorgar el consentimiento informado es una característica necesaria de la población investigada. En dichas circunstancias el médico habría de solicitar el consentimiento informado al representante legal, si bien, de no encontrarse dicho representante disponible y de no poderse retrasar la investigación, el estudio podría llevarse a cabo sin consentimien- 
to informado, siempre que las razones específicas para incluir a individuos con una enfermedad que no les permite otorgar consentimiento informado hayan sido estipuladas en el protocolo de la investigación y el estudio haya sido aprobado por un comité de ética de la investigación. En todo caso, el consentimiento para mantenerse en la investigación debería obtenerse a la menor brevedad posible del individuo o de un representante legal.

La declaración de Helsinki establece la existencia de obligaciones éticas por parte de los autores, directores y editores con respecto a la publicación de los resultados de su investigación. En relación con los autores se establece que tienen el deber de tener a disposición del público los resultados de su investigación en seres humanos y que son responsables de la integridad y exactitud de sus informes, debiendo aceptar las normas éticas de entrega de información. Se consigna igualmente la necesaria publicación tanto de los resultados negativos e inconclusos como de los positivos (habiendo, de lo contrario, de quedar a disposición del público). En todo caso, la publicación tiene que citar las fuentes de financiación, las afiliaciones institucionales y los conflictos de intereses.

Por último, la declaración recoge en su apartado $\mathrm{C}$ los principios aplicables cuando la investigación médica se combina con atención médica. En este sentido, se dispone que el médico puede combinar la investigación médica con la atención médica, sólo en la medida en que tal investigación acredite un justificado valor potencial preventivo, diagnóstico o terapéutico y si el médico tiene buenas razones para creer que la participación en el estudio no afectará de manera adversa a la salud de los pacientes que toman parte en la investigación. En este punto, uno de los aspectos que ha generado mayores interrogantes en la esfera científica es el relativo a la legitimidad del uso de placebo en el marco de las referidas investigaciones. La declaración de Helsinki dispone sobre el particular que los posibles beneficios, riesgos, costos y eficacia de todo procedimiento nuevo deben ser evaluados mediante su comparación con la mejor intervención probada existente, excepto en las siguientes circunstancias:

El uso de placebo, o de ningún tratamiento, en estudios para los que no exista intervención probada existente.

Cuando por razones metodológicas, científicas y apremiantes el uso de un placebo es necesario para determinar la eficacia y la seguridad de una intervención que no implique un riesgo, efectos adversos graves o daño irreversible para los pacientes que reciben el placebo o ningún tratamiento. En todo caso, la propia Declaración pone de manifiesto que se habrá de actuar con enorme cuidado para evitar abusos de esta opción.

Por otro lado, se establece que al término de la investigación todos los pacientes que participan en el estudio tienen derecho ser informados sobre sus resultados y a compartir cualquier beneficio, por ejemplo, acceso a intervenciones identificadas como beneficiosas en el estudio o a otra atención apropiada. Asimismo, el médico debe informar cabalmente al paciente de 
los aspectos de la atención que tienen relación con la investigación, no cabiendo que la negativa del paciente a participar en una investigación o su decisión de retirarse perturbe la relación médico-paciente ${ }^{15}$.

El apartado 35 regula el uso compasivo del medicamento o producto o técnica objeto de ensayo estableciendo que cuando en la atención de un enfermo las intervenciones probadas hayan resultado ineficaces o no existan, el médico, después de pedir consejo de experto, con el consentimiento informado del paciente o de un representante legal autorizado, podrá permitirse usar intervenciones no comprobadas, si, a su juicio, ello da alguna esperanza de salvar la vida, restituir la salud o aliviar el sufrimiento.

El conjunto de principios referidos constituye el eje sobre el que se ha establecido el marco de investigación y experimentación humana, tanto en la esfera supranacional (Consejo de Europa, Unión Europea, etc.), como en la esfera comparada a nivel de las distintas democracias occidentales. Se puede concluir que dichos principios se han erigido en criterios generales informadores de los ordenamientos jurídicos en materia de investigación biomédica.

\subsection{Informe Belmont.}

Una ulterior etapa en este proceso de consolidación en la esfera internacional, por medio de instrumentos de naturaleza no jurídica, de principios en materia de experimentación humana, viene constituida por el informe Belmont del año $1978^{16}$. En el mismo se establecían los denominados «principios éticos básicos» ${ }^{17}$, que deben ser entendidos como aquellos criterios generales que sirven como justificación para muchos de los preceptos éticos particulares y evaluaciones de las acciones humanas. El referido informe fue fruto de la creación en 1974 en Estados Unidos de la National Commission for the protection of Human Subject of Biomedical and Behavioral Research (Comisión Nacional para la protección de los seres humanos sujetos a investigación biomédica y conductual) y se elaboró como respuesta a los casos

${ }^{15}$ En este sentido, Sánchez CARo, J., «Protección de los sujetos participantes. Postulados éticos en la investigación con seres humanos. Ensayos con menores e incapaces», cit., p. 59.

${ }^{16}$ De acuerdo con GAFo el referido informe significó un verdadero espaldarazo a la incipiente Bioética y marcó un nuevo estilo en los enfoques metodológicos de esta disciplina, dejando de analizarse los problemas bioéticos de acuerdo con los códigos deontológicos y pasando a hacerlo en torno a los principios citados y a partir de procedimientos derivados de ellos. Véase GAFO, J., «Historia de una nueva disciplina: la Bioética», en Romeo Casabona, C. M. (coord.), Derecho biomédico y bioética, Ministerio de Sanidad y Consumo-Comares, Granada, 1998, p. 99.

17 Respecto a la clasificación cuatrimembre posterior, véase BeAuchamp, T.L./ChILDRESs, J. F., Principles of biomedical ethics, Oxford University Press, New York, 1979. 
de utilización abusiva de seres humanos en experimentaciones científicas llevados a cabo en Estados Unidos ${ }^{18}$.

En primer lugar, se consigna el principio de respeto por las personas (también conocido como principio de autonomía). De manera general, ello implica tanto que los seres humanos deben ser tratados como entes autónomos como que las personas cuya autonomía se encuentra disminuida deben ser objeto de protección. El principio de respeto por las personas se divide en dos requerimientos morales distintos: por un lado, la exigencia de aceptar la autonomía y, por otro, la de proteger a aquellos con autonomía reducida. Como pone de manifiesto el propio Informe Belmont una persona autónoma es un individuo capaz de deliberación sobre sus objetivos personales y de actuar de acuerdo con dicha deliberación. Respetar la autonomía es dar valor a las opiniones y opciones de las personas autónomas a la vez que evitar la obstrucción de sus acciones salvo cuando son claramente perjudiciales para terceros. Mostar falta de respeto por un agente autónomo es repudiar los juicios de esa persona, denegar a un individuo la libertad de actuar sobre la base de dichos juicios u ocultarle información necesaria para realizar un juicio, cuando no existen razones justificadas para hacerlo. Como queda de manifiesto en virtud de la argumentación anterior, el principio de respeto por las personas entronca fundamentalmente con la cuestión del consentimiento informado, eje de la reflexión actual en materia de experimentación huma$\mathrm{na}^{19}$, y aspecto incorporado como fundamental en la legislación comparada de la práctica totalidad de los países occidentales ${ }^{20}$.

En segundo lugar, se consagra el principio de beneficencia. Se puede afirmar que el Informe Belmont contenía en este punto dos subprincipios: el de beneficencia y el de no maleficencia, pues se establecían tanto la exigencia de no hacer daño como la de extremar los posibles beneficios y minimizar los potenciales riesgos. De acuerdo con el Informe Belmont la máxima hipocrática «no hacer daño» ha sido un principio fundamental de la ética mé-

${ }_{18}$ Tal como pone de manifiesto GonzÁlez-Torre, A. P., «Investigación científica (Capítulo V)», cit., p. 236; el mismo, Bioética y experimentación con seres humanos, cit., pp. 15 y ss.

${ }^{19}$ Véase GAFO, J., «Historia de una nueva disciplina: la Bioética», cit., p. 103.

20 Según ABELlÁn-García SÁncheZ actualmente el consentimiento informado ha sido elevado a la categoría de derecho humano fundamental. Así, para nuestro Tribunal Supremo el consentimiento informado encuentra su fundamento y apoyo en la misma Constitución española en la exaltación de la dignidad de la persona, pero sobre todo en la libertad, a partir del reconocimiento de la autonomía del individuo para elegir entre diversas opciones vitales de acuerdo con sus propios intereses y preferencias. Véase ABELLÁNGARCíA SÁNCHEZ, F., «El consentimiento informado, la intimidad y la confidencialidad de los datos del paciente en los ensayos clínicos, con especial referencia a las obligaciones en materia de protección de datos personales», en Sánchez CARO, J. / Abellán, F. (Coordinadores), Ensayos clínicos en España, cit., pp. 93 y ss. 
dica y el propio Claude Bernard la extendió a la esfera de la investigación, afirmando que nadie debe lesionar a otra persona con independencia de los beneficios que puedan derivarse para terceros. En este sentido, cabe afirmar que el principio de beneficencia ostenta una importancia primordial a la hora de definir el rol del médico, si bien se ha puesto de manifiesto el peligro de que, aisladamente considerado, pueda conducir a actitudes paternalistas por parte de los profesionales de la salud ${ }^{21}$. De cualquier manera, las exigencias derivadas del principio de beneficencia afectan tanto a los investigadores individuales como a la sociedad en su conjunto, pues se extienden tanto a los proyectos de investigación particulares como al conjunto de la acción experimental a nivel social.

Por último, el informe Belmont configura como principio fundamental en este punto el de justicia, en un intento de determinar criterios válidos para la asignación de cargas y beneficios en el marco de la investigación con seres humanos. El propio informe acepta que diferencias fundadas en la experiencia, edad, privación, competencia, mérito y posición constituyen en ocasiones criterios que justifican un tratamiento diferencial para ciertos fines. Se citan igualmente una serie de formulaciones ampliamente aceptadas dirigidas a distribuir justamente cargas o beneficios. Dichas formulaciones serían las siguientes ${ }^{22}: 1$ ) a cada persona una participación igual; 2) a cada persona de acuerdo con sus necesidades individuales; 3 ) a cada persona de acuerdo con sus esfuerzos individuales; 4) a cada persona de acuerdo con su contribución social; 5) a cada persona de acuerdo con sus méritos.

El principio de justicia ostenta una importancia decisiva en materia de experimentación ${ }^{23}$, pues plantea cuestiones como la legitimidad del empleo de determinados grupos de sujetos (normalmente pertenecientes a las clases sociales más desfavorecidas o a minorías étnicas objeto de discriminación) en el marco de los procesos de investigación, redundando posteriormente los beneficios de manera ordinaria en favor de los grupos más acomodados ${ }^{24}$.

${ }^{21}$ Véase GAfo, J., «Historia de una nueva disciplina: la Bioética», cit., pp. 101 y s.

22 Se refiere a los criterios sentados por el Informe Belmont en relación con el particular, SÁnchez CARo, J., «Protección de los sujetos participantes. Postulados éticos en la investigación con seres humanos. Ensayos con menores e incapaces», cit., p. 62.

${ }^{23}$ GonzÁlez-Torre se muestra crítico con la plasmación, en materia de experimentación, del principio de justicia en el marco del Convenio sobre Derechos Humanos y Biomedicina, pues si bien el Convenio establece en su art. 3 que las partes, teniendo en cuenta las necesidades de la sanidad y los recursos disponibles, habrán de adoptar las medidas adecuadas con el fin de garantizar un acceso igualitario a los beneficios de una sanidad de calidad apropiada, ello no es objeto de concreción posterior en relación con la investigación con seres humanos. Véase GonzÁlez-Torre, A. P., «Investigación científica (Capítulo V)», cit., p. 248.

${ }^{24}$ Acertadamente, GonZÁLEZ-TorRe pone de manifiesto una problemática ulterior que atenta contra el principio de justicia, consistente en la posibilidad, en el marco de in- 
A tratar de erradicar dichas prácticas viene el referido principio de justicia cuya relevancia en esta esfera resulta indubitada.

Otro aspecto relevante relacionado con el principio antedicho es el desarrollo de ensayos clínicos en países emergentes (o incluso subdesarrollados) con el fin de eludir las exigencias más estrictas para la realización de los mismos en países desarrollados (fundamentalmente desde el punto de vista de la normativa aplicable) siendo posteriormente los beneficiarios primarios (y en muchas ocasiones exclusivos) de dichos nuevos productos o técnicas los habitantes del llamado primer mundo.

\subsection{La Declaración Universal sobre Bioética y Derechos Humanos de la UNESCO (19 octubre de 2005) ${ }^{25}$.}

De acuerdo con su artículo 1 (Alcance) dicha declaración trata las cuestiones vinculadas con la medicina, las ciencias de la vida y las tecnologías conexas aplicadas a los seres humanos, teniendo en cuenta sus dimensiones sociales, jurídicas y ambientales. Si bien la declaración se orienta primariamente a los estados y ostenta un carácter eminentemente transnacional ${ }^{26}$, también establece criterios, cuando procede, para guiar las decisiones de individuos, grupos, comunidades, instituciones y empresas (tanto públicas como privadas).

Entre los objetivos de la declaración el artículo 2 incluye el reconocimiento de la importancia de la libertad de investigación científica y las repercusiones beneficiosas del desarrollo científico y tecnológico, destacando al mismo tiempo la necesidad de que esa investigación y los consiguientes adelantos se realicen en el marco de los principios éticos enunciados en la

vestigaciones terapéuticas con importantes expectativas de éxito, de que determinadas minorías desfavorecidas se encuentren discriminadas en el desarrollo de dicha experimentación. Resulta, por ello necesario, que todos los segmentos sociales (por ejemplo, mujeres y minorías) participen de las investigaciones y estén representados en ellas, en atención a los posibles beneficios que se derivarán de los ensayos. Muchas veces estas personas serán tentadas para participar en ensayos no terapéuticos, pero difícilmente se encontrarán entre los grupos en los que se experimentan terapias innovadoras. Véase GonzÁlez-Torre, A.P., Bioética y experimentación con seres humanos, cit., pp. 82 y ss.

${ }^{25}$ En la esfera de la UNESCO cabe mencionar igualmente la Declaración Universal sobre el Genoma Humano y los Derechos Humanos (11 de noviembre de 1997), que aborda oportunamente las cuestiones vinculadas con la investigación sobre el genoma humano y las condiciones de ejercicio de la actividad científica.

${ }^{26}$ Para una ampliación sobre el particular véase Romeo Casabona, C.M. / De Miguel BERIAIN, I., «Ámbito de aplicación de la Declaración Universal sobre Bioética y Derechos Humanos», en Romeo Casabona, C. M. (coord..), Hacia una Bioética Universal. La Declaración Universal sobre Bioética y Derechos Humanos, Instituto Roche-Cátedra Interuniversitaria de Derecho y Genoma Humano, [en línea], Bilbao, 2006 [citado el 1 de octubre de 2011], pp. 11 y ss., disponible en Internet: [http://www.catedraderechoygenomahumano.es/images/monografias/Revista_UNESCO.pdf] 
Declaración y respeten la dignidad humana, los derechos humanos y las libertades fundamentales (art. 2, apartado d). En cuanto a los principios de la declaración directamente aplicables en la esfera de la investigación científica en el ámbito de la salud humana cabría citar los de respeto a la dignidad humana y los derechos humanos (art. 3) ${ }^{27}$, potenciación de los beneficios directos e indirectos para los pacientes, los participantes en la investigación y otras personas concernidas y reducción al máximo de los efectos nocivos para las personas (art. 4), autonomía y responsabilidad individual (art. 5), consentimiento (art. 6) incluyendo las oportunas previsiones en relación con las personas que carecen de la capacidad para consentir (art. 7), respeto a la vulnerabilidad humana y a la integridad personal (art. 8), privacidad y confidencialidad (art. 9), igualdad, justicia y equidad (art. 10), no discriminación y no estigmatización (art. 11), respeto de la diversidad cultural y del pluralismo (art. 12), solidaridad y cooperación (art. 13), responsabilidad social y salud (art. 14), aprovechamiento compartido de los beneficios (art. 15), protección de las generaciones futuras (art. 16) y protección del medio ambiente, la bioesfera y la biodiversidad (art. 17). Por otro lado, especial importancia en el contexto de la investigación con seres humanos ostenta el art. 19 de la Declaración que establece que se deberían crear, promover y apoyar, al nivel que corresponda, comités de ética independientes, pluridisciplinarios y pluralistas con miras, entre otros aspectos, a evaluar los problemas éticos, jurídicos, científicos y sociales pertinentes suscitados por los proyectos de investigación relativos a los seres humanos. Asimismo, el art. 22.2 de la Declaración dispone que los estados deberían alentar la creación de comités de ética independientes, pluridisciplinarios y pluralistas ${ }^{28}$.

\subsection{Documentos del Consejo de Organizaciones Internacionales de las Ciencias Médicas (CIOMS), de la Organización Mundial de la Sa- lud (OMS) y de la Conferencia Internacional sobre Armonización de los Requerimientos Técnicos para el Registro de Fármacos de Uso Humano (ICH).}

El Consejo de Organizaciones Internacionales de las Ciencias Médicas (CIOMS) es una organización internacional no gubernamental que tiene re-

${ }^{27}$ En este plano, Nicolás JiméNEZ destaca acertadamente la importancia de la plasmación en el art. 3.2 de la Declaración del principio de primacía del ser humano (utilizando una dicción literal similar a la empleada por el Convenio de Derechos Humanos y Biomedicina del Consejo de Europa), véase Nicolás JimÉnEz, P., «La medicina individualizada frente a la Declaración Universal sobre Bioética y Derechos Humanos», en Romeo Casabona, C. M. (coord.), Hacia una Bioética Universal. La Declaración Universal sobre Bioética y Derechos Humanos, cit., p. 32.

${ }_{28}$ En este sentido, véase Romeo MaLAnda, S., «Impacto de la Declaración Universal de la UNESCO sobre Bioética y Derechos Humanos en el ordenamiento jurídico español», en Romeo Casabona, C. M. (coord.), Hacia una Bioética Universal. La Declaración Universal sobre Bioética y Derechos Humanos, cit., p. 38. 
laciones oficiales con la Organización Mundial de la Salud, habiendo sido fundada bajo los auspicios de la propia OMS y de la UNESCO en 1949. La CIOMS ha elaborado distintos documentos relevantes en el ámbito de la los criterios éticos para el desarrollo de investigación biomédica en seres humanos. Por un lado, las Pautas Éticas Internacionales para la Investigación Biomédica en Seres Humanos (Ginebra, 2002)29 y, por otro, las Guías Operacionales para Comités de Ética que evalúan Investigación Biomédica (Ginebra, 2000). Las primeras se dirigen a orientar, particularmente a los países de escasos recursos, en la definición de pautas nacionales sobre ética de la investigación biomédica, aplicando estándares éticos en condiciones locales y estableciendo o redefiniendo mecanismos adecuados para la evaluación ética de la investigación en humanos. Dicho texto establece principios éticos generales, un preámbulo y 21 pautas con una introducción y una breve descripción de anteriores instrumentos y criterios $^{30}$.

Específicamente en la esfera de los ensayos clínicos en relación con productos farmacéuticos la OMS elaboró las Pautas para Buenas Prácticas Clínicas en Ensayos de Productos Farmacéuticos (1995) ${ }^{31}$, cabiendo citar en dicho ámbito igualmente las Pautas de la Conferencia Internacional sobre armonización de los requerimientos técnicos para el registro de fármacos para uso humano ${ }^{32}$.

\subsection{Normativa comunitaria y española sobre ensayos clínicos con me- dicamentos de uso humano y productos sanitarios.}

Si bien del ámbito del Título II de la Ley 14/2007, de 3 de julio, de Investigación Biomédica (Investigaciones que implican procedimientos invasivos en seres humanos) quedan excluidos los ensayos clínicos en la esfera del medicamento y los productos sanitarios, objeto de una regulación específica en virtud de la legislación sectorial, procede en este punto poner de

${ }^{29}$ La versión de 2002 constituye la tercera existente, tras la de 1982 (Propuesta de Pautas Éticas Internacionales para la Investigación Biomédica en Seres Humanos) y la de 1993.

30 Véase Consejo De Organizaciones Internacionales De Las Ciencias Médicas (Cioms) / Organización Mundial De La SAlud, Pautas Éticas Internacionales para la Investigación Biomédica en Seres Humanos, [en línea], Ginebra, 2002 [citado el 1 de octubre de 2011], disponible en Internet: [http://www.ub.edu/rceue/archivos/Pautas_Eticas_Internac.pdf]

31 Véase World Health Organisation, Guidelines for Good Clinical Practice (GCP) for trials on pharmaceutical products, [en línea], 1995 [citado el 1 de octubre de 2011], disponible en Internet: [http://www.who.int/medicinedocs/collect/medicinedocs/pdf/ whozip13e/whozip13e.pdf]

32 Véase International Conference On Harmonisation Of Technical Requirements For Registration Of Pharmaceutical For Human Use (Ich), Guidelines, [en línea], [citado el 6 de diciembre de 2010], disponible in Internet: [http://www.ich.org/cache/ compo/276-254-1.html] 
manifiesto la existencia de una profusa normativa tanto a nivel de la Unión Europea como en la esfera interna (básicamente, trasponiendo las disposiciones comunitarias y adaptándolas a la realidad española) en relación con el particular, cuya analogía con la materia estudiada resulta importante.

En el marco de la Unión Europea la cuestión de los ensayos clínicos con medicamentos de uso humano ha sido objeto de oportuna regulación en virtud de la Directiva 2001/20/CE del Parlamento Europeo y del Consejo, de 4 de abril de 2001, relativa a la aproximación de las disposiciones legales, reglamentarias y administrativas de los Estados miembros sobre la aplicación de buenas prácticas clínicas en la realización de ensayos clínicos de medicamentos de uso humano ${ }^{33}$ y de la Directiva 2005/28/CE de la Comisión, de 8 de abril de 2005, por la que se establecen los principios y las directrices detalladas de las buenas prácticas clínicas respecto a los medicamentos en investigación de uso humano, así como los requisitos para autorizar la fabricación o importación de dichos productos.

A nivel español, el referido acervo comunitario ha sido objeto de la oportuna recepción en virtud de la Ley 29/2006, de 29 de julio, de garantías y uso racional de los medicamentos y productos sanitarios ${ }^{34}$ y del Real Decreto 223/2004, de 6 de febrero, por el que se regulan los ensayos clínicos con medicamentos ${ }^{35}$. En este sentido, el Título III de la Ley 29/2006 (De las garantías de la investigación de los medicamentos de uso humano) regula los ensayos clínicos con medicamentos. La propia Exposición de Motivos de la ley destaca como novedad y como garantía de transparencia, la posi-

${ }^{33}$ Actualmente la misma se encuentra en proceso de revisión. En relación con el particular, véase European Commission-Health And Consumers Directorate-General, Revision of the 'Clinical Trials Directive'2001/20/EC. Concept paper submitted for public consultation, [en línea], Bruselas, 09/02/2011 [citado el 1 de octubre de 2011], disponible in Internet: [http://ec.europa.eu/health/files/clinicaltrials/concept_paper_02-2011.pdf]

${ }^{34}$ Ley 29/2006, de 26 de julio, de garantías y uso racional de los medicamentos y productos sanitarios (Boletín Oficial del Estado, 27 de julio de 2006, n 178) cuyo título III aborda, bajo la rúbrica «De las garantías de la investigación de los medicamentos de uso humano», los ensayos clínicos con medicamentos. Dicha ley derogó la Ley 25/1990, de 20 de diciembre, del Medicamento (Boletín Oficial del Estado, 22 de diciembre de 1990, n 306).

35 Real Decreto 223/2004, de 6 de febrero, por el que se regulan los ensayos clínicos con medicamentos (Boletín Oficial del Estado, 7 de febrero de 2004, ${ }^{\circ} 33$ ), que supuso la incorporación a la normativa nacional de la Directiva 2001/20/CE, del Parlamento europeo y del Consejo, de 4 de abril de 2001, relativa a la aproximación de las disposiciones legales, reglamentarias y administrativas de los Estados miembros sobre la aplicación de buenas prácticas clínicas en la realización de ensayos clínicos de medicamentos de uso humano. Respecto a los estudios observacionales en la esfera del medicamento, véase el Real Decreto 1344/2007, de 11 de octubre, por el que se regula la farmacovigilancia de medicamentos de uso humano (Boletín Oficial del Estado, 1 de noviembre de 2007, $\mathrm{n}^{\mathrm{o}}$ 262) -en concreto, en el ámbito de los estudios post-autorización-. 
bilidad de que la Administración sanitaria pueda publicar los resultados de los ensayos clínicos cuando dicha publicación no se haya llevado a cabo por el promotor en plazo y siempre que los mencionados resultados permitan concluir que el producto presenta modificaciones de su perfil de eficacia o de seguridad; y ello, porque se toma en especial consideración el interés que, tanto para los pacientes que han participado en el ensayo como para los médicos y para la población en general, reviste el poder conocer los resultados del mismo, si de éstos se deriva que el medicamento plantea problemas de eficacia o de seguridad. Como eje de todo ensayo clínico en esta esfera se establece el necesario respeto a los derechos fundamentales de la persona y a los postulados éticos que afectan a la investigación biomédica (siguiéndose a estos efectos los de la Declaración de Helsinki), y la necesidad de que se cumplan las normas de buena práctica clínica como requisitos indispensables para garantizar la idoneidad del ensayo. Del mismo modo se mantienen las garantías de indemnización para los sujetos que pudieran verse perjudicados por su participación en los ensayos clínicos mediante la exigencia del aseguramiento previo de los daños y perjuicios que pudieran derivarse de aquéllos. En este sentido, el art. 61 Ley 29/2006 establece para los ensayos clínicos con medicamentos un régimen de responsabilidad del promotor, investigador y el centro u hospital en que se hubiera llevado a cabo análogo al que la Ley de Investigación Biomédica configura para el caso de experimentaciones que impliquen procedimientos invasivos en seres humanos.

Específicamente en relación con la práctica de ensayos clínicos con medicamentos en nuestro país ostenta particular relevancia el Real Decreto 223/2004, de 6 de febrero, que supuso la incorporación a la normativa nacional de la Directiva 2001/20/CE, del Parlamento europeo y del Consejo, de 4 de abril de 2001, relativa a la aproximación de las disposiciones legales, reglamentarias y administrativas de los Estados miembros sobre la aplicación de buenas prácticas clínicas en la realización de ensayos clínicos de medicamentos de uso humano. Desde el punto de vista de su contenido, el referido Real Decreto supone el necesario desarrollo por vía reglamentaria de la legislación (en sentido estricto) concurrente en dicha esfera ${ }^{36}$.

${ }^{36}$ En este sentido, procede poner de manifiesto la aplicación tanto de la Ley 29/2006 como del Real Decreto 223/2004 a la esfera de los ensayos clínicos con productos sanitarios a tenor de la disposición adicional $3^{\mathrm{a}}$ de la ley (Aplicación de la Ley a los productos sanitarios, de higiene personal y cosméticos. «1. De conformidad con lo dispuesto en esta Ley, se determinarán reglamentariamente las condiciones y requisitos que cumplirán los productos sanitarios para su fabricación, importación, investigación clínica, distribución, comercialización, puesta en servicio, dispensación y utilización, así como los procedimientos administrativos respectivos, de acuerdo con lo establecido en la normativa de la Unión Europea») y de la disposición adicional única del Real Decreto 223/2004 (Ensayos clínicos con productos sanitarios. «Los ensayos clínicos con productos sanitarios se regirán por los principios recogidos en este Real Decreto en lo que les resulte de aplicación»). 
Si bien la normativa anterior se refiere exclusivamente al ámbito de los ensayos clínicos con medicamentos de uso humano así como con productos sanitarios, ostenta incidencia en nuestra materia de estudio por la analogía con la regulación existente para los ensayos clínicos no farmacológicos.

\section{EL ANTECEDENTE INMEDIATO: LA CONVENCIÓN DEL CONSEJO DE EUROPA SOBRE LOS DERECHOS DEL HOMBRE Y LA BIOMEDICINA Y SU PROTOCOLO ADICIONAL RELATIVO A LA INVESTIGACIÓN BIO- MÉDICA DE 25.1.2005.}

\subsection{La Convención del Consejo de Europa sobre los Derechos del Hombre y la Biomedicina.}

El capítulo V del Convenio sobre Derechos Humanos y Biomedicina del Consejo de Europa se dedica a la investigación científica. Tras establecer en su art. 15 la regla general en virtud de la cual se consagra la libertad de investigación específicamente en el ámbito de la medicina y la biología (si bien, como resulta obvio, dicha libertad no es absoluta, pues se encuentra limitada por los derechos fundamentales de los individuos implicados), el art. 16 establece los criterios de protección de las personas que se someten a un experimento y el art. 17 hace lo propio en relación con las personas que no tengan capacidad para expresar su consentimiento a un experimento. Finalmente, el art. 18 se consagra a la experimentación con embriones in vitro, cuestión que queda fuera del objeto del presente trabajo y da lugar a una problemática específica abordada de manera suficientemente amplia por la doctrina nacional y comparada (así, en relación con la utilización de embriones sobrantes con fines de investigación o la mal denominada clonación terapéutica -en su caso, clonación para investigación-).

Otros preceptos del Convenio de Biomedicina relevantes en relación con la investigación biomédica son el art. 2 (que establece que el interés y el bienestar del ser humano deben prevalecer sobre el interés exclusivo de la sociedad o de la ciencia), el art. 4 (prescribe para toda intervención en el ámbito de la sanidad, incluyendo la experimentación, el respeto a las normas y obligaciones profesionales, así como a las normas de conducta aplicables a cada caso), art. 5 (exigencia de consentimiento informado en la esfera sanitaria), art. 21 (proscripción de que el cuerpo o sus partes sean fuente de aprovechamiento) y art. 24 (derecho de toda persona que ha sufrido un daño injustificado a resultas de una intervención a una reparación equitativa en las condiciones y modalidades previstas por la ley) ${ }^{37}$.

De manera específica, en su capítulo $V$ el Convenio de Oviedo exige una serie de condiciones para la práctica de investigaciones con seres humanos (art. 16):

${ }^{37}$ En este sentido, GonzÁlez-Torre, A. P., «Investigación científica (Capítulo V)», cit., p. 236. 
la inexistencia de un método alternativo al experimento con seres humanos de eficacia comparable. Ello implicaría que la investigación no deberá ser autorizada si resultados análogos pueden ser obtenidos por otros medios. De acuerdo con el Informe Explicativo a la Convención ${ }^{38}$ tampoco debe autorizarse el recurso a métodos invasivos si otros métodos no invasivos o menos invasivos pueden ser empleados con efectos similares.

Que los riesgos en que puede incurrir la persona no sean desproporcionados en relación con los beneficios esperables del experimento.

Aprobación del proyecto por parte de una autoridad competente ${ }^{39}$ después de haber realizado un estudio sobre su pertinencia científica, comprendida una evaluación de la importancia del experimento, así como un estudio multidisciplinar de su aceptabilidad en el plano ético.

Información adecuada suministrada a la persona que se presta al experimento en relación con sus derechos y las garantías previstas por la ley para su protección.

Consentimiento otorgado libre, expresamente y por escrito con posibilidad de revocación del mismo en todo momento. De acuerdo con dicha previsión no resultaría suficiente en esta esfera un consentimiento tácito.

En cuanto a la protección de las personas que no tengan capacidad para prestar su consentimiento a un experimento, el art. 17 Convenio de Oviedo establece que únicamente podrá llevarse a cabo una investigación sobre dichos sujetos bajo las siguientes premisas:

Que se cumplan los requisitos fijados en el art. 16 (arriba citados) con excepción del relativo al consentimiento, que, por definición, en este caso no puede ser prestado válidamente.

Que los resultados previstos supongan un beneficio real y directo para su salud.

Que el experimento no pueda realizarse con eficacia comparable en individuos que puedan prestar su consentimiento. Ello implica que el recurso a personas incapaces para prestar su consentimiento debe constituir la única posibilidad, no resultando suficiente con que no se encuentren voluntarios entre personas capaces.

Que se haya dado específicamente y por escrito la autorización de su representante, de una autoridad o de una persona o institución designada por la ley.

${ }^{38}$ Council Of Europe, Convention for the protection of Human Rights and dignity of the human being with regard to the application of biology and medicine: Convention on Human Rights and Biomedicine. Explanatory Report, [en línea], 1997 [citado el 1 de octubre de 2011], apartado 98, disponible en Internet: [http://conventions.coe.int/Treaty/ en/Reports/Html/164.htm]

39 El Convenio en este punto no concreta las características de la instancia de control a que se refiere, tal como pone de manifiesto GonzÁlez-Torre, A. P., «Investigación científica (Capítulo V)», cit., p. 237. 
Que la persona no exprese su rechazo al mismo.

Incluso puede prescindirse del requisito del beneficio directo para el sujeto del experimento en el caso de sujetos que no pueden prestar su consentimiento ${ }^{40}$, siempre que se den el resto de condiciones mencionadas, y que además, por un lado, el experimento suponga para la persona un riesgo o un inconveniente mínimo, y por otro lado, tenga por objeto, mediante una mejora significativa del conocimiento del estado de la persona, de su enfermedad o de su trastorno, contribuir a lograr en determinado plazo resultados que permitan obtener un beneficio para la persona afectada o para personas de la misma categoría de edad o que padezcan la misma enfermedad o trastorno, o que presenten las mismas características.

La distinción que traza el art. 17 Convenio entre supuestos de beneficio directo para el sujeto sometido a experimentación frente a casos donde el mismo no concurre nos remite a la importante diferenciación entre investigación terapéutica y no terapéutica. Siguiendo a González-Torre ${ }^{41}$ cabe conceptuar la primera como la aplicación a pacientes específicos de tratamientos cuya eficacia no ha sido establecida desde el punto de vista científico pero que se espera tengan un efecto positivo sobre la situación del enfermo, mientras que en el segundo caso se pretende la obtención de un conocimiento científico que no supone un beneficio directo para la persona sometida al ensayo. La importancia de la diferenciación radica en la ponderación del riesgo asumible, lógicamente mayor cuando se presume la producción, en caso de éxito del ensayo, de un efecto beneficioso en el participante. La delimitación antedicha no es acogida de manera genérica en el Convenio, si bien subyace al criterio que acoge el art. 17 Convenio específicamente en la esfera de la experimentación con incapaces, limitando en casos de investigación no terapéutica la admisibilidad de la misma a los casos en los que implique un riesgo y carga mínimos ${ }^{42}$.

En principio, la investigación biomédica a desarrollar deberá respetar los postulados anteriores que constituyen el marco genérico establecido por

${ }^{40}$ De acuerdo con GonzÁLEZ-Torre algunos autores han empleado la habilitación del art. 17 Convenio en relación con la posibilidad de investigar con personas incapaces (no exigiéndose de manera absoluta el beneficio directo para el sujeto participante) para afirmar que nos encontramos ante un caso en el que el interés social prevalece sobre el de los sujetos individuales. Véase GonzÁlez-Torre, A.P., «Investigación científica (Capítulo V)», cit., p. 236. Como se ha puesto de manifiesto supra, en la línea de proscribir de manera absoluta la investigación con sujetos incapaces se pronunciaba el Código de Nüremberg.

${ }^{41}$ Véase GonzÁlez-Torre, A .P., «Investigación científica (Capítulo V)», cit., pp. 252 y s.

${ }^{42}$ Asimismo, resulta de interés establecer la distinción entre investigación terapéutica y práctica médica habitual. En este sentido, véase GonzÁlez-Torre, A. P., Bioética y experimentación con seres humanos, cit., pp. 41 y ss. 
el Convenio sobre Derechos Humanos y Biomedicina en relación con el particular. No obstante, la existencia de un Protocolo destinado a abordar específicamente esta materia añade requisitos ulteriores, que dado que han sido mayoritariamente asumidos por la legislación española posterior, procede tomar oportunamente en consideración ${ }^{43}$.

\subsection{Protocolo Adicional al Convenio sobre Derechos Humanos y la Bio- medicina, relativo a la Investigación Biomédica.}

En desarrollo de esta normativa, el Consejo de Europa abrió a la firma el 25.1.2005 el Protocolo Adicional al Convenio de los Derechos Humanos y la Biomedicina, relativo a la investigación biomédica, que cuenta en la actualidad con 22 estados firmantes (entre los cuales no se encuentra España) y con 7 ratificaciones ${ }^{44}$, entrando en vigor en dichos estados el 1 de septiembre de 2007 (salvo Georgia que ratificó posteriormente y para la que entró en vigor el 1 de agosto de 2008 y Turquía que ratificó el 21/9/2011 y donde la entrada en vigor fue a fecha $1 / 1 / 2012$ ).

El referido Protocolo se compone de cuarenta artículos integrados en doce capítulos (Objeto y ámbito de aplicación; Disposiciones generales; Comités de Ética; Información y consentimiento; Protección de las personas incapaces de consentir a la investigación; Situaciones especificas; Seguridad y supervisión; Confidencialidad y derecho a la información; Investigación en países no partes del Protocolo; Infracción de las disposiciones de este Protocolo; Relación entre este Protocolo y otras disposiciones y reexamen de este Protocolo; Cláusulas finales). El Protocolo se refiere a todas las actividades de investigación en el ámbito de la salud que impliquen intervenciones ${ }^{45}$

${ }^{43}$ Como pone de manifiesto acertadamente GonzÁlez-Torre el Convenio es un Convenio marco que establece normas generales comunes, dejando para los protocolos adicionales la regulación de cuestiones más detalladas, como en este caso la investigación biomédica. Véase GonzÁlez-Torre, A. P., «Investigación científica (Capítulo V)», cit., p. 234.

44 Datos a 16 de mayo de 2012.

45 A efectos del Protocolo se entiende por intervención, tanto aquellas de naturaleza física, como cualquier otra en la medida en que implique un riesgo para la salud psicológica de la persona afectada. Por lo tanto, el término intervención se emplea aquí en un sentido amplio, incluyendo cuestionarios, entrevistas e investigaciones observacionales que tengan lugar en el contexto de un protocolo de investigación biomédica si implican un peligro de naturaleza psicológica. De acuerdo con el Informe Explicativo al Protocolo, cuestionarios o entrevistas pueden conllevar un riesgo para la salud psicológica del participante en la investigación si incluyen preguntas de naturaleza íntima capaces de resultar en un daño psicológico. No obstante, en este contexto, una angustia emocional leve y temporal no habría de ser considerada como daño psicológico. CounCIL Of Europe, Additional Protocol to the Convention on Human Rights and Biomedicine concerning Biomedical Research. Explanatory Report, [en línea], 2005 [citado el 1 de octubre de 2011], apartado 17, disponible en Internet: [http://conventions.coe.int/Treaty/ 
en seres humanos (integrando en dicha esfera a embriones y fetos in vivo), excluyendo la experimentación con embriones in vitro.

En este punto, cabe distinguir entre investigación médica y práctica médica innovativa, derivada de la intención que subyace a la intervención. En el caso de la practica médica la única finalidad es la de beneficiar al paciente individual, no la obtención de conocimiento para beneficio general, a pesar de que dicho conocimiento puede emerger de la experiencia clínica obtenida. En el caso de la investigación biomédica la intención primaria es la de mejorar el conocimiento de manera que los pacientes en general puedan beneficiarse del mismo. No obstante, un individuo participante en la investigación puede no beneficiarse de aquella.

El capítulo II del Protocolo Adicional establece las disposiciones generales y contiene criterios comúnmente aceptados en la esfera de las investigaciones que implican procedimientos invasivos en seres humanos. De esta manera se consagran la primacía de los intereses del ser humano sobre los de la sociedad y la ciencia (art. 3), la libertad de investigación sujeta a las previsiones del protocolo y demás disposiciones legales destinadas a garantizar la protección del ser humano (art. 4), la ausencia de alternativas de efectividad comparable (art. 5), la exigencia de que la investigación no implique para el sujeto riesgos y cargas desproporcionados a sus beneficios potenciales (art. 6), la necesidad de que todo proyecto de investigación sea aprobado por el órgano competente tras un examen independiente acerca de su valor científico (art. 7) y, finalmente, el requerimiento de que la experimentación se encuentre científicamente justificada (art. 8).

Particular relevancia ostenta el art. 6 Protocolo pues da acogida, como principio general en materia de investigación en seres humanos, a la distinción entre experimentación con beneficio directo para los participantes (investigación terapéutica) y aquella que no implica tal beneficio (investigación no terapéutica), admitiendo un mayor nivel de riesgo en la primera dado el efecto sobre la salud del sujeto sometido al ensayo que en el caso de la segunda ${ }^{46}$. Con carácter general el precepto referido establece que la investigación no puede implicar para el ser humano riesgos y cargas desproporcionados a su potencial beneficio, pero matiza adicionalmente, en relación con los casos de investigación que no tienen un potencial de producir

\footnotetext{
EN/Reports/Html/195.htm]

${ }^{46}$ Como pone de manifiesto Deutsch la diferenciación tiene su razón de ser porque en cualquier experimentación de tipo científico (no terapéutica) se deben ponderar los riesgos que supone para el sujeto sometido a ella frente al beneficio que suponga para la ciencia en general. Al ser conceptos totalmente distintos lo anterior no resultará fácil. Por otro lado, en la experimentación terapéutica los riesgos y beneficios para los pacientes que toman parte en el ensayo están situados al mismo nivel. Véase Deutsch, E., «La declaración de Helsinki y la Convención Europea de Bioética. Problemas asociados a la regulación de la experimentación médica», cit., p. 187.
} 
un beneficio directo en la salud de los sujetos participantes, que la misma no podrá llevarse a cabo más que si no supone ningún riesgo o carga inaceptable para los participantes.

El capítulo III del Protocolo se dedica a los Comités de Ética (que, en España, al amparo de la Ley de Investigación Biomédica se denominan Comités de Ética de la Investigación). En este sentido se exige en el art. 9 el sometimiento de todo proyecto de investigación a un examen independiente sobre su aceptabilidad ética por parte de un Comité de Ética, siendo el objeto del análisis multidisciplinar referido el garantizar la dignidad, los derechos, la seguridad y el bienestar de los participantes en la investigación. La conclusión a la que llegue el Comité mencionado debe encontrarse debidamente fundada. En relación con este precepto ostenta enorme importancia precisar el alcance del concepto de multidisciplinariedad, que necesariamente debe atender al equilibrio en cuestiones tales como la composición de los comités citados con base en criterios como género y diversidad cultural y no sólo a la formación en distintas áreas científicas o académicas de sus integrantes.

Un aspecto fundamental en relación con el trabajo de los Comités de Ética es garantizar su independencia, cuestión expresamente establecida en el art. 10 Protocolo, impidiéndose que su actuación se encuentre indebidamente mediatizada por influencias externas inadecuadas. Asimismo, se impone a los miembros de los Comités la declaración de cualquier circunstancia que pueda conducir a un conflicto de intereses. Finalmente, se establece que toda la información necesaria para la evaluación ética del proyecto de investigación debe ser suministrada por escrito al Comité de Ética correspondiente (art. 11). El propio Protocolo contiene un apéndice en el que se explicita el conjunto de la información que ha de ser trasladada al Comité de Ética (agrupada en los siguientes bloques: descripción del proyecto; participantes, consentimiento e información y otras informaciones) al amparo de lo previsto en el art. 11.

En virtud del art. 12 Protocolo se establece la proscripción de influencias indebidas, incluyendo las de naturaleza económica, en relación con los sujetos participantes en la investigación. La cuestión citada ostenta particular relevancia en aquellas situaciones en las que un sujeto confía en otro (así, típicamente en la relación doctor/paciente cuando el primero es a su vez investigador) pudiéndose ejercer presión sobre el segundo para que participe en la experimentación. El Informe Explicativo al Protocolo pone de manifiesto que en dichas situaciones la mejor práctica consistirá en solicitar el consentimiento por parte de un tercero neutral o en la recepción de la contestación por parte de este último en relación con la participación en la investigación. No obstante, se admite la previsión de algún tipo de compensación para los participantes sin que ello pueda considerarse influencia indebida, siempre que la misma resulte adecuada a las cargas e inconvenientes generados y que no suponga un incentivo a asumir riesgos que de otra forma no se considerarían aceptables. En todo caso, en esta materia debe prestarse 
particular atención en los casos de personas dependientes (privados de libertad, estudiantes, p.ej. de medicina, militares, trabajadores sanitarios, etc.) y vulnerables con el fin de evitar toda influencia indebida, que resulta más factible en estos casos.

De cualquier manera, la cuestión de la posible remuneración/compensación (en este caso, el eufemismo de los términos encubre la voluntad de legitimar una práctica sin la cual el desarrollo de muchos ensayos clínicos sería del todo imposible) de los sujetos participantes en una investigación resulta problemática, pues es evidente que particularmente en experimentaciones sin beneficio directo para los participantes, la existencia de alguna forma de incentivo dinerario constituye una razón importante para que muchos sujetos tomen parte en la misma ${ }^{47}$. No obstante, la legislación tanto supranacional (art. 21 Convenio sobre Derechos Humanos y Biomedicina, que proscribe que el cuerpo humano o sus partes sean fuentes de aprovechamiento) como nacional se muestran absolutamente contrarias a la admisión de toda forma de remuneración en este ámbito, aceptándose exclusivamente la compensación de las molestias causadas como consecuencia de la participación en la experimentación.

El capítulo IV aborda los aspectos relativos a la información y al consentimiento, cuestiones centrales en el marco de la investigación biomédica directamente vinculadas con el principio de respeto a la persona o autonomía. En particular, se establece la necesidad de que los sujetos participantes en la experimentación reciban información adecuada de manera comprensible, debiendo la misma ser documentada. La información debe extenderse al objetivo, el plan general y a los riesgos y beneficios posibles del proyecto de investigación y debe incluir la opinión del Comité de Ética. Ulterior información específica a suministrar viene establecida en el art. 13 Protocolo. En relación con el particular, procede poner de manifiesto la importancia de que la información suministrada no resulte meramente generalista, sino que pormenorice al sujeto cuestiones como los riesgos a asumir en virtud de la intervención proyectada en sus circunstancias concretas y personales (atendiendo para ello a factores como edad o patología subyacente). Asimismo, la información debe ser transmitida de manera adecuada a las características del sujeto receptor, tomando en consideración su edad, formación, etc.

Finalmente en materia de consentimiento el art. 14 exige que el mismo sea libre, expreso, informado, específico y documentado, proscribiendo que el rechazo a consentir o la retirada del mismo pueda dar lugar a forma alguna de discriminación. Resulta particularmente interesante que dicho precepto establezca la necesidad de llevar a cabo los ajustes procedentes en el caso de sujetos cuya capacidad para consentir pueda resultar dudosa con el fin de comprobar la efectiva concurrencia de dicha capacidad. De acuerdo con

${ }^{47}$ En este sentido, véase González-Torre, A. P., «Investigación científica (Capítulo V)», cit., p. 250 . 
el Informe Explicativo al Protocolo dicha previsión abarca a las personas que no hayan sido declaradas incapaces para prestar su consentimiento por un órgano judicial, pero cuya capacidad para consentir resulte cuestionable debido a un accidente o a un estado persistente o que ha empeorado. En todo caso, el precepto no exigiría que los ajustes establecidos específicamente para estos supuestos se desarrollaran en todo caso en el marco de los tribunales de justicia, pudiendo ser implementados con arreglo a los estándares profesionales.

El Protocolo Adicional al Convenio sobre Derechos Humanos y Biomedicina, relativo a la Investigación Biomédica, regula en sus capítulos V y VI las cuestiones relacionadas con la protección de las personas incapaces para prestar su consentimiento y una serie de situaciones específicas, respectivamente.

En relación con el primero de los puntos referidos, el art. 15 exige un conjunto de condiciones para poder desarrollar investigaciones en personas incapaces (siendo estos requisitos sustancialmente los mismos que los establecidos en la Ley de Investigación Biomédica, por lo que serán objeto de oportuno desarrollo en dicho apartado). Por otro lado, en relación con la investigación con incapaces el art. 16 viene a concretar la información previa a suministrar (tanto a la persona encargada de prestar su consentimiento como al sujeto afectado, a pesar de que este último no se encuentre en situación de prestar su consentimiento, salvo que no pueda recibir dicha información), mientras el art. 17 define los conceptos de mínimo riesgo y mínima carga en el marco de la experimentación con seres humanos (condición requerida, entre otras, por el art. 15.2 Protocolo para llevar a cabo investigación en incapaces que no produzca beneficio directo en la salud de los mismos). En este sentido, se considera que el riesgo es mínimo si, tomando en consideración la naturaleza y la dimensión de la intervención, resulta esperable que producirá, a lo sumo, un impacto negativo en la salud de la persona afectada leve y temporal. Por otro lado, la mínima carga se daría si resulta esperable que el malestar será, como mucho, temporal y muy leve para el sujeto concernido. Al concretar el grado de carga para el individuo, una persona que goce de su confianza puede evaluarla cuando se estime apropiado. El Informe Explicativo al Protocolo considera como ejemplos de investigaciones con mínima carga y riesgo las siguientes:

obtención de fluidos corporales sin intervención invasiva (saliva, muestras de orina, etc).

Cuando se están obteniendo muestras de tejidos, por ejemplo, durante una intervención quirúrgica, tomar pequeñas muestras suplementarias.

Tomar una muestra de sangre de una vena periférica o una muestra de sangre capilar.

Extensiones menores de medidas diagnósticas no invasivas empleando equipamiento técnico, como exámenes sonográficos, electrocardiogramas tras reposo, una exposición a rayos $\mathrm{X}$, etc. 
No obstante, podrían existir participantes para los cuales algunos de estos procedimientos no impliquen un riesgo o carga estimable como meramente mínimo. Por ello, la concreción de dichos aspectos debe realizarse sobre una base individual.

En materia de situaciones específicas (Capítulo VI Protocolo) se regulan de manera particular las investigaciones durante el embarazo y la lactancia (art. 18), aquellas practicadas en personas en situación de emergencia clínica (art. 19) y las llevadas a cabo en personas privadas de libertad (art. 20).

Respecto del primer supuesto citado, el artículo 18 protege a la mujer, feto y al embrión in vivo durante el embarazo, así como a la mujer lactante sometida a investigación. El precepto implica que si los resultados de la experimentación no tienen potencial de beneficio directo para la salud de la mujer, embrión, feto o del niño después del nacimiento no puede existir más que una carga y riesgo mínimo. Además, en este supuesto y con respecto a mujeres embarazadas, la investigación debe ir dirigida a beneficiar a otras mujeres en relación con la reproducción o a otros embriones, fetos o niños y sólo será aceptable si dicha investigación no puede realizarse en mujeres que no se encuentren en dicho estado. Asimismo, se establece que si la experimentación se lleva a cabo en una mujer lactante, deben adoptarse particulares cautelas para evitar cualquier impacto adverso en la salud del niño.

Particular relevancia ostenta el capítulo VII del Protocolo Adicional relativo a la seguridad y la supervisión. En este punto, el art. 21 se refiere a la minimización de riesgos y cargas, ámbito en el que se incluye la necesidad de que la investigación se lleve a cabo únicamente bajo la supervisión de un profesional clínico que posea la cualificación y le experiencia precisa. Por otro lado, el art. 22 aborda la evaluación del estado de salud de los sujetos participantes, exigiendo de los investigadores la adopción de todas las medidas necesarias para la comprobación del estado de salud de los potenciales participantes en la investigación con carácter previo a su inclusión en la misma, a fin de excluir a aquellos sometidos a un riesgo importante. En este sentido, el Informe Explicativo al Protocolo pone de manifiesto que las medidas necesarias pueden incluir un examen clínico de los sujetos, pero ello no resultará necesario en todos los casos. Asimismo, se establece que cuando la investigación se lleve a cabo en personas en edad fértil debe prestarse especial atención al posible impacto negativo en un embarazo actual o futuro y en la salud del embrión, feto o niño.

Una ulterior previsión en relación con el desarrollo de las investigaciones se establece en el art. 23 dedicado a la no interferencia con las intervenciones clínicas necesarias, impidiendo que la investigación demore o prive a los individuos sometidos a la misma de los procedimientos preventivos, diagnósticos o terapéuticos precisos. En el caso de investigación asociada con la prevención, diagnóstico o tratamiento, los participantes asignados a grupos de control deben tener asegurado el acceso a métodos probados de 
prevención, diagnóstico o tratamiento ${ }^{48}$. Por lo tanto, es de esperar que se emplee un método contrastado de tratamiento disponible en el país o región (entendida como un conjunto de países vecinos o incluso como un área más amplia) de referencia. Asimismo, se establece en relación con el uso de placebo, la admisibilidad del recurso al mismo únicamente cuando no exista un método de efectividad comprobada o cuando la renuncia o la retirada de tales métodos no represente un riesgo o carga inaceptable para el paciente. Este último aspecto (carácter aceptable o no del riesgo o carga) debe ser establecido por el Comité de Ética y por el organismo competente correspondiente.

Finalmente se prevé que el proyecto de investigación sea reexaminado si ello resulta pertinente a la luz de los nuevos desarrollos científicos o eventos acaecidos en el curso de la experimentación (art. 24) con el fin de determinar si la misma debe ser interrumpida o si deben introducirse cambios en el protocolo. Con base en dicho precepto cabría la finalización anticipada de la investigación, siempre que ello responda a situaciones que así lo legitimen, habiendo de informarse de las mismas al organismo competente. El Informe Explicativo al Protocolo recoge como razones aceptables de finalización el que se ponga de manifiesto de manera estadísticamente clara que el tratamiento experimental es significativamente peor que el tratamiento estándar, por lo que no resultaría éticamente aceptable continuar con el proyecto. En cambio, no sería una legitimación adecuada para la terminación el evitar una respuesta comercial adversa a la vista de un probable resultado negativo, resultado que, en principio, habrá de ser hecho público.

En cuanto al capítulo VIII Protocolo Adicional se dedica a cuestiones claves en relación con la investigación biomédica, tales como la confidencialidad de la información personal obtenida durante el proceso experimentador (art. 25), derecho a saber con respecto a toda información de salud y personal derivada de la práctica investigadora (art. 26), la obligación de ofrecer a los individuos participantes toda información relevante para su calidad de vida actual o futura derivada de la investigación (art. 27) y la necesaria disponibilidad de los resultados por parte de los Comités de Ética u organismos competentes, participantes y público en general (art. 28). Este

${ }^{48}$ Cuestión cuya relevancia es oportunamente puesta de manifiesto por parte de GonZÁlez-Torre, autor que remite en este punto al concepto de equilibrio clínico (clinical equipoise) que, siguiendo a BEAUCHAMP / CHILDRESs cabría definir como la situación que se produce cuando «basándose en las pruebas disponibles, los miembros de la comunidad médica de expertos relevantes están igualmente inclinados hacia cualquiera de las estrategias de tratamiento que se están probando en el ensayo clínico aleatorio (ECA), porque tienen las mismas incertidumbres frente a ellas y se sienten igualmente cómodos con las ventajas y desventajas conocidas de los tratamientos sometidos a prueba. Ningún paciente, pues, recibirá un tratamiento que se sepa que es menos efectivo o más peligroso que una alternativa disponible». Véase González-Torre, A. P., Bioética y experimentación con seres humanos, cit., p. 55. 
último precepto resulta particularmente reseñable pues al fijar la obligación por parte de los investigadores de enviar un sumario o informe de la investigación al comité de Ética o al organismo competente y de hacer públicos los resultados obtenidos en un plazo razonable, incluso si son negativos, se está evitando la duplicación innecesaria de investigaciones que empleen personas debido a la falta de publicación de los resultados anteriores, y se pretende proscribir la supresión de resultados negativos o positivos por razones comerciales u otras no científicas.

Finalmente, se abordan cuestiones tales como la investigación en estados no parte del Protocolo (capítulo IX), la infracción de las disposiciones del Protocolo (capítulo X), la relación entre el Protocolo y otras disposiciones y reexamen del Protocolo (capítulo XI) y las cláusulas finales (capítulo XII). En definitiva, el Protocolo Adicional establece un marco completo y adecuado para la regulación de la investigación biomédica, cuyo ámbito de aplicación resulta más amplio que el capítulo II de la Ley de Investigación Biomédica (Investigaciones que implican procedimientos invasivos en seres humanos) pues no excluye la investigación en la esfera farmacéutica y de los productos sanitarios. Dicha normativa del Consejo de Europa ha servido de referente directo para la regulación española sobre el particular en virtud de la Ley 14/2007, de 3 de julio.

\section{ANÁLISIS DE LA LEY DE INVESTIGACIÓN BIOMÉDICA.}

\subsection{Visión de conjunto del Título II.}

A la hora de proceder al estudio del Título II de la Ley de Investigación Biomédica, resulta imprescindible remitirse al Protocolo adicional al Convenio del Consejo de Europa sobre los Derechos Humanos y la Biomedicina, relativo a la Investigación Biomédica (25.1.2005) del que trae directamente causa, hasta el punto de poder afirmar que la mayor parte de los artículos que configuran dicho título han sido transcritos literalmente del referido protocolo.

En este sentido, cabe poner de manifiesto el acierto de la decisión adoptada por el legislador español en este punto, pues supone otorgar rango legal a nivel interno a una normativa de referencia internacional, adelantando así el proceso que exige que, para que ello tenga lugar, se proceda a la firma y ratificación del instrumento por parte de España (lo cual aún no se ha llevado a cabo en el caso de nuestro país).

Siguiendo la propia exposición de motivos de la Ley de Investigación Biomédica resulta oportuno destacar que el Título II («Investigaciones que implican procedimientos invasivos en seres humanos») constituye el primero que aborda una materia específica, pues el Título I de la norma integra las disposiciones generales. Ello pone de manifiesto la relevancia otorgada por el legislador a la materia relativa a las investigaciones que implican procedimientos invasivos en seres humanos (excluyendo los meramente observa- 
cionales), no sólo por la posición sistemática que ocupa dicho Título II en el conjunto del texto, sino igualmente por el importante nivel de garantías previstas al efecto.

Desde el punto de vista material, resulta oportuno subrayar el carácter complementario que la regulación prevista en la Ley de Investigación Biomédica ostenta en relación con la normativa ya existente en virtud de la Ley de garantías y uso racional de los medicamentos y productos sanitarios, y relativa a los ensayos clínicos con dichos productos. De esta manera queda completado en el Derecho español el marco normativo sobre investigaciones invasivas ( $\mathrm{y}$, por lo tanto, no meramente observacionales ${ }^{49}$ ) en las que los seres humanos son sujetos participantes directos.

Desde un punto de vista estructural procede destacar que el título II Ley de Investigación Biomédica se divide en cinco capítulos, lo que evidencia la amplitud y heterogeneidad de la materia objeto de regulación. En cuanto a los rasgos básicos de cada uno de los capítulos integrantes del Título II Ley de Investigación Biomédica, el primero de ellos (arts. 13-15) aborda los principios generales en que estas investigaciones deben desenvolverse, incluyendo de manera pormenorizada los aspectos vinculados al consentimiento y desglosando la información precisa que ha de suministrarse necesariamente a los sujetos participantes en la investigación.

El capítulo II (arts. 16-18) gira bajo la denominación «Evaluación, autorización y aseguramiento del daño» y supone la concreción en la esfera de las experimentaciones que implican procedimientos invasivos en seres humanos del principio de evaluación de la actividad investigadora, cuya mayor dificultad consistirá en llevarla a cabo sin vulnerar el contenido esencial de la libertad de investigación ${ }^{50}$. Las disposiciones contenidas en el capítulo referido pretenden, de acuerdo con la propia Exposición de Motivos de la ley, reducir al máximo los perjuicios que pudieran derivarse de investigaciones que supongan procedimientos invasivos en seres humanos. A dichos efectos se recogen una serie de previsiones, incluyendo además de las medidas profilácticas necesarias las cuestiones vinculadas con el aseguramiento del

${ }^{49}$ De acuerdo con el art. 3 Ley de Investigación Biomédica («Definiciones») se entiende por estudio observacional el «estudio realizado sobre individuos respecto de los cuales no se modifica el tratamiento o intervención a que pudieran estar sometidos ni se les prescribe cualquier otra pauta que pudiera afectar a su integridad personal». Los anteriores quedan excluidos del ámbito del capítulo II Ley de Investigación Biomédica, pues de acuerdo con el título II de dicha norma su esfera de aplicación se limita a aquellas investigaciones que implican procedimientos invasivos en seres humanos.

${ }^{50}$ Así lo pone de manifiesto, Gómez SÁnchez, Y., «La libertad de creación y producción científica en la ley de investigación biomédica: objeto, ámbito de aplicación y principios generales de la ley», en SÁnchez-CARo, J. / ABELlán, F. (Coords.), Investigación Biomédica en España, Comares, Granada, 2007, p. 27. 
daño que pueda sobrevenir a los sujetos participantes a resultas de la investigación llevada a cabo sobre los mismos.

El capítulo III del Título II Ley de Investigación Biomédica (arts. 19-21) se refiere a las «Situaciones específicas»y, en concreto, procede a regular los aspectos particulares ligados a la investigación durante el embarazo y la lactancia, así como en el supuesto de menores e incapaces y en el de personas incapaces de consentir debido a su situación clínica. No cabe duda de que nos encontramos ante casos que exigen un plus de protección, dada la particular vulnerabilidad del sujeto, y así lo ha entendido el legislador que ha procedido a configurar un marco legal específico para estos supuestos. Ello entronca, por otro lado, con la profusa normativa internacional existente en estas materias, y con la tradición histórica desde el Código de Nüremberg.

El cuarto capítulo (arts. 22-25) regula los sistemas de seguridad y supervisión en el proceso de investigación. Ello ostenta una particular importancia práctica a la vista de la necesidad de garantizar la absoluta indemnidad de los intereses de los sujetos participantes. En este punto, la Ley de Investigación Biomédica exige la evaluación del estado de salud de los participantes en la investigación, alude a la no interferencia en las intervenciones clínicas de éstos y configura un completo sistema de comprobaciones que deben efectuarse durante el curso de la experimentación en el marco de las cuales ostenta particular relevancia la labor del Comité de Ética de la Investigación.

Finalmente, el capítulo V (arts. 26-27) fija una serie de obligaciones a las que tradicionalmente no se ha prestado la importancia que merecen en la esfera de las experimentaciones con seres humanos, pero a las que la doctrina y legislación tanto nacional como comparada asignan un rol fundamental con el fin de garantizar la transparencia en el proceso investigador. En concreto, se trata de la necesidad de informar a los participantes en la investigación de los datos relevantes para su salud que puedan obtenerse durante su desarrollo, así como la de dar publicidad a sus resultados.

\section{2. Ámbito de aplicación del Título II Ley de Investigación Biomédica.}

Una primera cuestión que procede analizar oportunamente es la relativa al ámbito de aplicación del Título II Ley de Investigación Biomédica. En este sentido, el hecho de que la esfera de la investigación con seres humanos a nivel de ensayos clínicos con medicamentos y productos sanitarios cuente con su propia normativa de referencia (Ley 29/2006, de 26 de julio, de garantías y uso racional de los medicamentos y productos sanitarios -Título III «De las garantías de la investigación de los medicamentos de uso humano»y Real Decreto 223/2004, de 6 de febrero, por el que se regulan los ensayos clínicos con medicamentos) determina que dicha materia quede excluida de la regulación de la Ley de Investigación Biomédica. Ello se encuentra expresamente establecido en el art. 1 de la norma (Objeto y ámbito de aplicación) que dispone que «la investigación biomédica a la que se refiere esta Ley incluye la investigación de carácter básico y la clínica, con la excepción 
en este último caso de los ensayos clínicos con medicamentos y productos sanitarios, que se regirán por su normativa específica». En virtud del dato anterior, el Título II de la ley quedará reservado exclusivamente para aquellas investigaciones con personas que no puedan incardinarse en la esfera del medicamento y del desarrollo de productos sanitarios. Si bien la mayor parte de los ensayos clínicos ${ }^{51}$ se vinculan al ámbito farmacológico, procede no caer en una simplista asociación entre ensayo clínico y medicamento ${ }^{52}$. No obstante, la prevalencia manifiesta de ensayos clínicos farmacológicos ha conllevado que aquellos que no ostentan dicha naturaleza adolezcan en muchos casos de una menor estandarización metodológica y, probablemente en numerosas ocasiones, de un menor rigor y validez ${ }^{53}$.

En segundo lugar, lo dispuesto en el Título II Ley de Investigación Biomédica únicamente resulta aplicable cuando la experimentación se desarrolle en nacidos, así como en embriones y fetos vivos en el útero (pues en este último caso, resulta indudable que incidirá sobre un nacido como es la embarazada, siendo dicha interpretación coherente con la dicción del art. 19 Ley de Investigación Biomédica). Ello supone que la actividad experimental

${ }^{51}$ Entendidos como aquellos estudios prospectivos realizados con el fin de evaluar las intervenciones que se han aplicado en más de dos grupos poblacionales creados al azar y que, por lo tanto, son comparables entre sí. Véase Xavier BonfiLl, X., «Situación actual de los ensayos clínicos no farmacológicos en España», cit., p. 11.

${ }^{52}$ Ejemplos de ensayos clínicos en intervenciones no farmacológicas pueden citarse, entre otros, los siguientes, Pico Soler, Ma. V., «Prevención del alcoholismo: estudios EMPA y EIBAL», en BonfILL, X. et al., Ensayos clínicos en intervenciones no farmacológicas, cit., pp. 17 y ss.; RodríGuez, F. A., «Ensayos clínicos en ejercicio físico y deporte», en BonfILl, X. et al., Ensayos clínicos en intervenciones no farmacológicas, cit., pp. 23 y ss.; Aleixandre Marti, E. / Casanova Matutano, M. A. et al., «Ensayo clínico de dos intervenciones de deshabituación tabáquica en atención primaria», en BonfILL, X. et al., Ensayos clínicos en intervenciones no farmacológicas, cit., pp. 37 y ss.; PLADEVALL VILA, M., «Intervenciones sobre cumplimiento terapéutico: a propósito de un ensayo clínico», en Bonfill, X. et al., Ensayos clínicos en intervenciones no farmacológicas, cit., pp. 45 y ss.; IzQuierdo, M., «Terapia génica», en Bonfill, X. et al., Ensayos clínicos en intervenciones no farmacológicas, cit., pp. 55 y ss.; Guerra, J. A., «Problemas de investigación en acupuntura», en BonfILl, X. et al., Ensayos clínicos en intervenciones no farmacológicas, cit., pp. 61 y ss.; SANCHO, J. J., «Ensayos clínicos en cirugía», en Bonfill, X. et al., Ensayos clínicos en intervenciones no farmacológicas, cit., pp. 69 y ss.; Targarona, E. Ma ., "Cirugía endoscópica y medicina basada en la evidencia», en BonfiLl, X. et al., Ensayos clínicos en intervenciones no farmacológicas, cit., pp. 75 y ss.; Kovacs, F. M., «Ensayos clínicos sobre la intervención neurorreflejoterápica para el tratamiento de la lumbalgia inespecífica», en Bonfill, X. et al., Ensayos clínicos en intervenciones no farmacológicas, cit., pp. 83 y ss.; SÁnchez MecA, J., «Aportación del metaanálisis en la evaluación de la psicoterapia», en Bonfill, X. et al., Ensayos clínicos en intervenciones no farmacológicas, cit., pp. 93 y ss.

${ }^{53}$ Argumentos sostenidos por Xavier Bonfill. Véase Bonfill, X., «Situación actual de los ensayos clínicos no farmacológicos en España», cit., p. 11. 
sobre preembriones in vitro, así como sobre embriones que hayan perdido su capacidad de desarrollo o sobre embriones o fetos muertos (incluyendo sus estructuras biológicas), cuestiones que han constituido uno de los focos fundamentales de polémica en relación con la investigación biomédica en España no se regirán por las disposiciones aquí estudiadas. Ello se deduce indefectiblemente del hecho de que la anterior sea una materia regulada en otros títulos de la Ley 14/2007, de 3 de julio, de Investigación Biomédica (Título III. Sobre la donación y el uso de embriones y fetos humanos, de sus células, tejidos u órganos y Título IV. Sobre la obtención y uso de células y tejidos de origen embrionario humano y de otras células semejantes), así como por la Ley 14/2006, de 26 de mayo, sobre Técnicas de Reproducción Humana Asistida ${ }^{54}$ (capítulo IV. Investigación con gametos y preembriones humanos).

No obstante, y aun cuando la investigación en embriones y fetos vivos en el útero se rige por lo dispuesto en el Título II Ley de Investigación Biomédica, resulta oportuno poner de manifiesto que respecto de los mismos únicamente cabrá la investigación terapéutica, es decir, la destinada a producir un beneficio directo en aquellos, dado que el art. 30 Ley de Investigación Biomédica (Limitaciones a la investigación con embriones y fetos vivos en el útero) dispone expresamente que exclusivamente podrán autorizarse intervenciones sobre el embrión o el feto vivos en el útero cuando tengan un propósito diagnóstico o terapéutico en su propio interés, sin perjuicio de lo previsto legalmente sobre la interrupción voluntaria del embarazo. La propia Exposición de Motivos de la ley establece que «la investigación con embriones y fetos vivos en el útero sólo podrá realizarse con propósito diagnóstico o terapéutico en su propio interés», por lo que admite expresamente la investigación con beneficio directo en estos casos.

Por último, a la hora de definir lo que se entiende por «investigaciones que implican procedimientos invasivos en seres humanos» como ámbito material del Título II de la ley, procede poner de manifiesto que el concepto aludido se opone a los denominados estudios observacionales, que no quedan sometidos a los importantes requerimientos legales configurados en el articulado de referencia, básicamente, por entenderse que no implican peligro significativo para los sujetos participantes. En todo caso, lo que debamos entender por «estudios observacionales» y por «procedimientos invasivos» viene legalmente determinado en el propio art. 3 Ley de Investigación Biomédica, disposición en la que se consignan un conjunto de definiciones, que resultan fundamentales a la hora de interpretar el sentido de la norma. De esta manera, «estudio observacional» lo será aquel «estudio realizado sobre individuos respecto de los cuales no se modifica el tratamiento o intervención a que pudieran estar sometidos ni se les prescribe cualquier otra pauta que pudiera afectar a su integridad

${ }^{54}$ Ley 14/2006, de 26 de mayo, sobre Técnicas de Reproducción Asistida. Boletín Oficial del Estado, 27 de mayo de 2006, nº 126. 
personal» (art. 3.m), mientras el «procedimiento invasivo» quedará integrado por «toda intervención realizada con fines de investigación que implique un riesgo físico o psíquico para el sujeto afectado» (art. 3.t).

Al hilo de la argumentación desarrollada al analizar el Protocolo al Convenio sobre Derechos Humanos y Biomedicina relativo a la Investigación Biomédica cuyo ámbito de aplicación se extiende al conjunto de las actividades de investigación en el ámbito de la salud que impliquen intervenciones en seres humanos, procede poner de manifiesto que, con base en las definiciones anteriores de la Ley de Investigación Biomédica, habría que considerar procedimiento invasivo el sometimiento del sujeto a cuestionarios o entrevistas en la medida en que puedan implicar un riesgo para la salud psicológica del participante en la investigación (normalmente si incluyen preguntas de naturaleza íntima capaces de derivar en un daño psicológico). En supuestos como los anteriores el carácter de la investigación (meramente observacional o invasiva) deberá ser concretado ex ante y adecuadamente ponderado, pues determina el sometimiento de la misma a normas concretas para su desarrollo.

\subsection{Capítulo I. Principios generales y requisitos de la información y consentimiento.}

Dicho capítulo (capítulo I, Título II Ley de Investigación Biomédica) se encuentra integrado por 3 preceptos (arts. 13-15) dedicados al consentimiento, los principios generales a los que deben someterse las referidas investigaciones y la información a suministrar a los sujetos participantes en la investigación, respectivamente.

A pesar de su ubicación sistemática, procede analizar en primer término el art. 14 Ley de Investigación Biomédica, disposición que ostenta una importancia decisiva pues aborda la cuestión de los principios generales por los que deben regirse las experimentaciones con seres humanos. Sólo de cumplirse los términos previstos en dicho artículo procederá llevar a cabo investigaciones que impliquen procedimientos invasivos. En concreto, se establecen tres criterios básicos:

Recurso a la misma sólo en ausencia de una alternativa de eficacia comparable.

La investigación no deberá implicar riesgos y molestias desproporcionadas en relación con los beneficios potenciales que se puedan obtener.

Finalmente, y cuando la investigación no tenga posibilidad de producir resultados de beneficio directo para la salud del sujeto participante en la misma, sólo podrá ser iniciada en el caso de que presente un riesgo y una carga mínimos, a juicio del Comité de Ética de la Investigación ${ }^{55}$ que deba

${ }^{55}$ De acuerdo con la Disposición transitoria tercera de la Ley de Investigación Biomédica (Comités Éticos de Investigación Clínica):

«Los Comités Éticos de Investigación Clínica dejarán de existir a partir del momento en que se constituyan los Comités de Ética de la Investigación. Hasta que dicho Comités 
evaluarla. En este sentido, el concepto de «riesgo y carga mínimos» se incluye entre las definiciones establecidas en el art. 3 apartado u de la ley, que lo conceptúa como «los impactos en la salud y las molestias que puedan sufrir los sujetos participantes en una investigación, y cuyos efectos sólo podrán ser de carácter leve y temporal».

A través de este precepto, que reproduce los arts. 5 y 6 del Protocolo adicional al Convenio de Derechos Humanos y Biomedicina relativo a la investigación biomédica ${ }^{56}$ se establecen criterios básicos en relación con los que debe desarrollarse la investigación con seres humanos.

En todo caso, el art. 14 Ley de Investigación Biomédica incide en un aspecto oportunamente destacado supra pero que procede reiterar, consistente en la distinción entre investigación con beneficio directo para el participante (investigación terapéutica) y la que no implica tal beneficio (investigación no terapéutica). Ello resulta oportuno al objeto de delimitar el nivel de riesgo admisible en cada una, que como destaca el propio art. 14 de la ley, será mayor en el caso de la primera.

$\mathrm{El}$ art. 13 relativo al consentimiento exige que el mismo sea expreso, específico y escrito, por parte del sujeto o de su representante legal, de acuerdo con los principios establecidos en el art. 4 Ley de Investigación Biomédica ${ }^{57}$. La cuestión del consentimiento informado constituye uno de los aspectos axiales en la esfera de la investigación biomédica ${ }^{58}$. Así queda de manifiesto

se constituyan, los Comités Éticos de Investigación Clínica que estén en funcionamiento en los centros que realicen investigación biomédica, podrán asumir las competencias de aquéllos».

${ }_{56}$ Únicamente procede reseñar que el art. 6.2 del Protocolo mencionado, para el caso de que la investigación no produzca ningún beneficio directo en el sometido a la misma se limita a exigir que no implique un riesgo o una carga inaceptable para el sujeto participante, por lo que parece más permisivo en este punto que la propia Ley de Investigación Biomédica que habla de riesgo y cargas mínimos.

57 El referido art. 13 Ley de Investigación Biomédica tiene su equivalente en el Protocolo adicional al Convenio de Derechos Humanos y Biomedicina del Consejo de Europa, relativo a la investigación biomédica en virtud del art. 14 de este último texto legal que, sin embargo, añade a lo anterior que el consentimiento puede ser libremente retirado por la persona en cualquier momento de la investigación (la Ley de Investigación Biomédica introduce dicha cláusula en el art. 15.4) y que prevé ajustes cuando la capacidad de la persona para consentir resulte dudosa con el fin de comprobar dicha eventualidad.

58 SÁNCHEZ CARO pone de manifiesto que el consentimiento informado constituye el exponente fundamental del principio de autonomía y la principal justificación para que se pueda actuar sobre el cuerpo del paciente. Dicho autor destaca cómo para la ley la cuestión esencial consiste en determinar el papel que tengan la información y el consentimiento; es decir, si lo relevante es la posición del médico, que en virtud del principio de beneficencia tiene como norte el objetivo del bienestar del paciente, construyéndose, en este caso, la relación alrededor del propio profesional sanitario, o si, por el contrario, el eje de la relación se articula en torno a la autonomía del paciente, quien, sobre la base 
con carácter general en relación con cualquier intervención en la esfera de la sanidad en virtud de la regulación del Convenio de Oviedo (art. 5) y de la Ley 41/2002, de 14 de noviembre, básica reguladora de la autonomía del paciente y de derechos y obligaciones en materia de información y documentación clínica (Capítulo IV. El respeto a la autonomía del paciente, en particular, arts. 8 a 10), y sectorialmente en el marco de las investigaciones con seres humanos en virtud del Protocolo Adicional al Convenio de los Derechos Humanos y la Biomedicina, relativo a la investigación biomédica (art. 14), de la Ley 29/2006, de 26 de julio, de garantías y uso racional de los medicamentos y productos sanitarios (art. 60.4) y del Real Decreto 223/2004, de 6 de febrero, por el que se regulan los ensayos clínicos con medicamentos (art. 7).

En primer lugar, procede poner de manifiesto que para que el consentimiento informado resulte válido debe ser, inexorablemente, otorgado por una persona competente, adecuadamente informada y voluntario ${ }^{59}$. La voluntariedad, como atributo del consentimiento se emplea aquí en el sentido de manifestación de la voluntad carente de coerción, manipulación o persuasión $^{60}$. La particularidad de la relación médico-paciente puede conducir a evidentes distorsiones en este punto; conviene aceptar que la posición prevalente en el binomio anterior es la que ocupa el médico, por lo que el paciente

de una información adecuada, de unos datos relevantes, queda en libertad para tomar la decisión que crea más oportuna. No obstante, advierte oportunamente SÁnCHEZ CARO que «aún reconociendo la importancia de la información y del consentimiento, parece obligado advertir, en este momento, que la complejidad médica nos puede presentar situaciones en las que el principio de autonomía no es relevante por sí solo, sino que tiene que ser objeto de ponderación junto con otros principios. Tal es el caso de la experimentación terapéutica, la investigación con y en seres humanos (...)»; dado que el presente trabajo se centra en el análisis de las investigaciones que implican procedimientos invasivos en seres humanos, procede en este punto tomar en consideración las particularidades concurrentes en materia de consentimiento. Véase SÁNCHEZ CARO, J., «El consentimiento previo a la intervención y la protección de los incapaces (Capítulo II)», en Romeo CASABona, C. M. (editor), El Convenio de Derechos Humanos y Biomedicina, Cátedra de Derecho y Genoma Humano-Editorial Comares, Bilbao-Granada, 2002, pp. 112 y s.

59 Véase Foster, C., The ethics of medical research in humans, Cambridge University Press, Cambridge, 2001, p. 57.

${ }^{60}$ Véase CAMPS, V., «El consentimiento informado y sus limitaciones», en CARNÉ, X. / Costa, J. et al., Problemas y controversias en torno al ensayo clínico, Fundación Dr. Antonio Esteve-Ediciones Doyma, Barcelona, 1998, p. 11. Dicha autora pone de manifiesto que el consentimiento debería ser el resultado de una opción libre no instrumentalizada por intereses opacos o pocos claros, pero que, no obstante, no siempre resulta fácil determinar dónde acaba la coacción y donde empieza la libertad del agente que debe consentir. Particularmente complejo resulta concretar en qué supuestos existe manipulación y, en especial, persuasión, máxime en una relación tan característica como la existente entre el médico y el paciente. 
puede temer que aquel no se encuentre satisfecho de su renuncia a participar en una determinada investigación o incluso considere que su médico nunca va a solicitarle algo malo para él. Ello le puede llevar a considerar que no hay razón alguna para rechazar cualquier intervención, incluso en la esfera de la investigación, que aquel le proponga ${ }^{61}$.

Conceptualmente la exigencia del consentimiento informado se vincula con el respeto a la autonomía individual. De acuerdo con Abellán-García Sánchez ${ }^{62}$ el término "consentimiento informado» alude a una teoría que ha sido elaborada dentro del contexto de la ética, el derecho y la medicina, pudiendo denotar, por tanto, matices muy diferentes para los especialistas de diversas disciplinas, según se trate de éticos, juristas o médicos. Fundamental a la hora de hablar de un consentimiento informado es la existencia de una información adecuada, transmitida de manera comprensible, es decir, apta para el nivel de conocimientos del receptor de la misma. "Consentimiento» e «información» constituyen, pues, conceptos indisolubles en la práctica biomédica moderna, y así queda consagrado de manera general en la normativa tanto nacional como internacional existente sobre el particular.

A la hora de trazar el marco normativo del consentimiento informado en derecho español, procede poner de manifiesto que inciden en esta materia el Convenio de Oviedo (art. 5) y la Ley 41/2002, Básica Reguladora de la Autonomía del Paciente (arts. 8 y ss.) ${ }^{63}$. De acuerdo con el art. 3 Ley 41/2002 cabría definir el consentimiento informado como «la conformidad libre, voluntaria y consciente de un paciente, manifestada en el pleno uso de sus facultades, después de recibir la información adecuada, para que tenga lugar una actuación que afecta a su salud». Específicamente, en el ámbito de los ensayos clínicos con medicamentos el Real Decreto 223/2004 define el consentimiento informado como la «decisión, que debe figurar por escrito y estar fechada y firmada, de participar en un ensayo clínico adoptada volunta-

${ }^{61}$ Véase Foster, C., The ethics of medical research in humans, cit., p. 61, quien considera que, de acuerdo con la premisa anterior, el médico nunca debería solicitar al paciente hacer algo que resulte dañoso, con independencia de que ello pueda redundar en futuros pacientes.

62 Véase Abellán-García SÁnchez, F., «El consentimiento informado, la intimidad y la confidencialidad de los datos del paciente en los ensayos clínicos, con especial referencia a las obligaciones en materia de protección de datos personales», cit., p. 91, quien sigue en este punto a Appelbaun, P. S. / Lidz, C. W. / Meisel, A., Informed Consent, New York, Oxford University Press, 1987. A nivel histórico la teoría del consentimiento informado, de acuerdo con Abellán-García SÁnchez, constituye uno de los productos de la interacción entre medicina y sociedad surgido fundamentalmente tras la Segunda Guerra Mundial ante la constatación de las atrocidades llevadas a cabo en los campos de exterminio nazis en el marco de experimentos con seres humanos.

${ }_{63}$ Previamente a la entrada en vigor de dicha norma en nuestro ordenamiento jurídico, la cuestión del consentimiento informado era objeto de regulación por parte de Ley 14/1986, General de Sanidad (art. 10.5 -información-y 10.6 -consentimiento-). 
riamente por una persona capaz de dar su consentimiento tras haber sido debidamente informada y documentada acerca de su naturaleza, importancia, implicaciones y riesgos $\rangle^{64}$. En cuanto a la forma de plasmación del consentimiento, si bien la Ley 41/2002 parte, como criterio general, de la validez del consentimiento verbal, prevé una serie de excepciones en las que el mismo necesariamente deberá figurar por escrito. En concreto, ello se establece en los supuestos de intervención quirúrgica, procedimientos diagnósticos y terapéuticos invasores y para la aplicación de todos aquellos procedimientos que supongan riesgos o inconvenientes de notoria y previsible repercusión negativa en la salud del paciente (art. 8.2 ley 41/2002). Asimismo, la propia Ley 41/2002 acepta expresamente en su art. 9.4 (art. 9. Límites del consentimiento informado y consentimiento por representación) que la práctica de ensayos clínicos y de técnicas de reproducción humana asistida se regirán por lo establecido con carácter general sobre mayoría de edad y por las disposiciones especiales de aplicación.

En definitiva, la Ley de Autonomía del Paciente prevé su carácter meramente supletorio en materia de consentimiento en relación con la regulación específica existente en la esfera de la investigación clínica ${ }^{65}$, por lo que habrá que atender a la normativa sectorial en este ámbito: en materia de medicamentos y productos sanitarios la Ley 29/2006, de 26 de julio, de garantías y uso racional de los medicamentos y productos sanitarios y el Real Decreto 223/2004, de 6 de febrero, por el que se regulan los ensayos clínicos con medicamentos; para el resto de experimentaciones que impliquen procedimientos invasivos en seres humanos rige el Título II de la Ley 14/2007, de 3 de julio, de Investigación Biomédica.

En consonancia con el criterio general establecido en la Ley de Autonomía del Paciente para los casos de procedimientos invasores, el art. 13 Ley de Investigación Biomédica, en relación específicamente con las investigaciones que impliquen procedimientos invasivos en seres humanos, prevé de manera taxativa que el consentimiento sea «expreso, específico y escrito por parte del sujeto o de su representante legal». La regulación en este punto de la ley española deriva de manera mimética de la normativa del Consejo de Europa, en concreto, del Protocolo Adicional relativo a la Investigación Biomédica, que dispone en su art. 14 la proscripción, salvo en supuestos excep-

${ }^{64}$ Véase Real Decreto 223/2004, de 6 de febrero, por el que se regulan los ensayos clínicos con medicamentos, art. 2 apartado $\mathrm{m}$.

${ }^{65}$ Disposición adicional $2^{\text {a }}$ Ley 41/2002. Aplicación supletoria

«Las normas de esta ley relativas a la información asistencial, la información para el ejercicio de la libertad de elección de médico y de centro, el consentimiento informado del paciente y la documentación clínica, serán de aplicación supletoria en los proyectos de investigación médica, en los procesos de extracción y trasplante de órganos, en los de aplicación de técnicas de reproducción humana asistida y en los que carezcan de regulación especial». 
cionales, de toda investigación en la que cada participante no haya prestado un consentimiento informado, libre, expreso, específico y consignado por escrito. De manera análoga, para el ámbito del medicamento y los productos sanitarios la Ley 29/2006 establece que «el sujeto del ensayo prestará su consentimiento libremente, expresado por escrito, tras haber sido informado sobre la naturaleza, importancia, implicaciones y riesgos del ensayo clínico» y el Real Decreto 223/2004 dispone que «el consentimiento se documentará mediante una hoja de información para el sujeto y el documento de consentimiento». En esta esfera, queda claramente vetada la posibilidad de que el consentimiento se exprese oralmente, salvo en los supuestos en los que el sujeto ostente un impedimento para escribir, en cuyo caso, el consentimiento podrá ser prestado por cualquier medio admitido en derecho que permita dejar constancia de su voluntad (art. 4 Ley de Investigación Biomédica) ${ }^{66}$.

Junto con la importancia del consentimiento como criterio rector de la validez de toda investigación de la naturaleza de la recogida en el Título II Ley de Investigación Biomédica, procede destacar el carácter esencial de la información a suministrar al sujeto participante, con el fin de que el mencionado consentimiento resulte realmente «informado». Ello queda tasado de manera expresa en el art. 15 Ley de Investigación Biomédica, artículo que tiene su correlato en el art. 13 Protocolo adicional sobre investigación biomédica. De acuerdo con el precepto de la ley española citado, que hace referencia a la información a suministrar a los sujetos participantes en la investigación, las personas a las que se solicite su participación en un proyecto de investigación recibirán previamente la necesaria información, debidamente documentada y en forma comprensible y cuando se trate de individuos con discapacidad, de forma adecuada a sus circunstancias. En este sentido, procede poner de manifiesto que se trata de una información pormenorizada, debidamente documentada y que debe ser transmitida en forma comprensible, es decir, de manera ajustada a las circunstancias personales del sujeto ${ }^{67}$.

${ }^{66}$ En este supuesto, el Real Decreto 223/2004, de 6 de febrero, por el que se regulan los ensayos clínicos con medicamentos, art. 2 apartado m y la Ley 29/2006, de 26 de julio, de garantías y uso racional de los medicamentos y productos sanitarios (art. 60.4) permiten otorgar el consentimiento de forma oral en presencia de, al menos, un testigo mayor de edad y con capacidad de obrar.

${ }^{67}$ Con carácter general, y al objeto de concretar el derecho a la información en la esfera de la biomedicina, cabe exigir que la referida información resulte inteligible para el receptor, veraz, adecuada y precisa, es decir, ajustada a la realidad y centrada en el problema o situación cuyo conocimiento sea necesario para asimilarla, debiendo contener todos los datos y elementos relevantes a la formación personal del juicio de valor. Finalmente deberá ser clara y neutral en el planteamiento de la decisión personal con el fin de permitir la decisión autónoma del receptor. En este sentido véase ALDAMA BAQUEDANO, C., «La protección de la intimidad y del derecho a la información (capítulo III)», en Romeo Casabona, C. M. (editor), El Convenio de Derechos Humanos y Biomedicina, cit., p. 153; Romeo Casabona, C. M. (Coord.)/Emaldi Cirión, A./Martín Uranga, A./ 
Entre los aspectos que debe consignar la referida información se incluyen necesariamente el propósito, el plan detallado, las molestias y los posibles riesgos y beneficios de la investigación.

Los extremos a especificar incluyen:

-Naturaleza, extensión y duración de los procedimientos a utilizar.

-Procedimientos preventivos, diagnósticos y terapéuticos disponibles.

-Medidas para responder a acontecimientos adversos en lo que concierne a los sujetos que participan en la investigación.

-Medidas para asegurar el respeto a la vida privada y a la confidencialidad de los datos personales, de acuerdo con la legislación sobre protección de datos de carácter personal ${ }^{68}$.

-Medidas para acceder a la información relevante para el sujeto, que surjan de la investigación o de los resultados totales.

-Medidas para asegurar una compensación adecuada en el caso de que el sujeto sufra algún daño.

-Identidad del profesional responsable de la investigación.

- Cualquier futuro uso potencial, incluyendo los comerciales, de los resultados de la investigación.

-Fuente de financiación del proyecto de investigación.

Incluso se establece la previsión de que, de no conocerse alguno de dichos extremos, existiría el compromiso explícito de completar la información cuando los referidos datos se encuentren disponibles.

El propio art. 15 aclara (cuestión que, de no quedar regulada expresamente también daría lugar a una remisión automática por razón de la materia) que en el supuesto de uso futuro o simultáneo de datos genéticos o de muestras biológicas en el curso de la investigación se estará a lo dispuesto en los capítulos II («Análisis genéticos y tratamiento de datos genéticos de carácter personal») y III («Utilización de muestras biológicas humanas con fines

Nicolás Jiménez, P./Mata Barranco, I. de la, Información y documentación clínica. Su tratamiento jurisprudencial (1990-1999), Ministerio de Sanidad y Consumo, Madrid, 2000, pp. 23 y ss.

${ }^{68}$ Dicha exigencia de información respecto al mencionado particular presupone la necesaria adopción de medidas en este ámbito con el fin de garantizar la confidencialidad de los mencionados datos personales, en la línea de lo dispuesto en el art. 25 (Consentimiento) Protocolo Adicional relativo a la investigación biomédica -precepto que carece de correlato en el Título II Ley de Investigación Biomédica-y que establece expresamente: «1. Toda información de carácter personal obtenida con ocasión de una investigación biomédica será considerada como confidencial y tratada de acuerdo con las reglas relativas a la protección de la vida privada.

2. La ley protegerá contra la divulgación inadecuada de toda otra información relativa a un proyecto de investigación que haya sido comunicada a un comité de ética en aplicación del presente Protocolo». En España, rige en este punto la Ley 15/1999, de 13 de diciembre, de protección de datos de carácter personal. 
de investigación biomédica») del Título V («Análisis genéticos, muestras biológicas y biobancos») de la Ley de Investigación Biomédica. En dichos capítulos se regulan pormenorizadamente aspectos tales como información previa a la realización de análisis genéticos, derecho a la información y a no ser informado, acceso a los datos genéticos por personal sanitario, etc.

Por último, el art. 15 completa el ciclo relativo a la información a suministrar al interesado, pues prevé específicamente en su apartado $4^{\circ}$ que los participantes en una investigación deberán ser informados de los derechos y salvaguardas previstas en la ley para su protección y, específicamente, de su derecho a rehusar el consentimiento o a retirarlo en cualquier momento sin que pueda verse afectado por tal motivo su derecho a la asistencia sanitaria.

Si analizamos la regulación de la información a suministrar en el marco del desarrollo de ensayos clínicos con medicamentos y productos sanitarios, podemos constatar la analogía en los aspectos fundamentales con la normativa derivada de la Ley de Investigación Biomédica, siendo, no obstante, esta última mucho más pormenorizada al detallar cada uno de los aspectos que deben incluirse en la información a suministrar al sujeto participante en el ensayo. En este sentido, la Ley 29/2006, de 26 de julio, de garantías y uso racional de los medicamentos y productos sanitarios dispone que el sujeto del ensayo clínico sea informado sobre la naturaleza, importancia, implicaciones y riesgos del mismo.

A pesar de que las normas relativas a la obtención del consentimiento informado resultan claras y taxativas, la monitorización de dicho proceso en diferentes países ha puesto de manifiesto importantes deficiencias y errores en el marco del mismo. Así la Food and Drug Administration norteamericana (FDA) evidenció que el 54\% de los investigadores cometen errores en el proceso de obtención del consentimiento informado ${ }^{69}$.

Como corolario al análisis de la Ley de Investigación Biomédica en materia de consentimiento informado en la esfera de las investigaciones que implican procedimientos invasivos en seres humanos procede poner de manifiesto las oportunas consideraciones formuladas por Victoria Camps ${ }^{70}$ en este punto. Por un lado, en relación con la propia práctica del consentimiento informado (como expresión del reconocimiento de la autonomía del pacien-

${ }^{69}$ Véase DAL-RÉ, R., «La protección de los sujetos participantes en los ensayos clínicos: supervisión de la conducción del ensayo clínico por el Comité Ético de Investigación Clínica», en CARné, X. / CostA, J. et al., Problemas y controversias en torno al ensayo clínico, cit., p. 17. Asimismo, dicho autor destaca que a pesar de que los Comités de Ética de la Investigación disponen en Estados Unidos de la posibilidad, en virtud de la autoridad conferida, de presenciar directamente o por terceros el proceso de obtención del consentimiento informado, ello constituiría una intromisión directa en el proceso de investigación, por lo que resulta preferible el control ex post.

70 Véase CAMPS, V., «El consentimiento informado y sus limitaciones», en CARNÉ, X. / Costa, J. et al., Problemas y controversias en torno al ensayo clínico, cit., p. 12. 
te) que debería constituir una forma de favorecer y mejorar el diálogo entre el médico y el enfermo, por lo que el mismo no puede convertirse en un mero trámite burocrático que materialmente ejecuta una enfermera, y que se materializa en la simple firma de un documento que se entrega al paciente/ participante, sin comprobar el grado de comprensión real por parte de aquel. Coincido en la observación de que para que el sujeto pueda tomar una decisión realmente libre ello implica necesariamente una "pérdida de tiempo» por parte del profesional sanitario, que se verá obligado a dar explicaciones que en muchos casos le resultarán demasiado elementales, pero que devienen fundamentales para asegurar la plena libertad del individuo.

\subsection{Capítulo II. Evaluación, autorización y aseguramiento del daño.}

El art. 16 prevé el ciclo de evaluación y autorización al que debe ser sometida toda investigación biomédica que comporte algún procedimiento invasivo en el ser humano. En el caso español se requiere, en consecuencia, de dichas dos fases, que deberán ser implementadas en cada caso, por el Comité y por el organismo legalmente establecidos. En primer lugar, la evaluación corresponde al Comité de Ética de la Investigación, debiendo ser previa a la autorización, favorable y debidamente motivada y fundada en los siguientes aspectos: idoneidad científica del proyecto, pertinencia, factibilidad y adecuación del investigador principal y equipo investigador. Realizada la evaluación por el referido Comité de Ética de la Investigación, y de resultar la misma favorable, procederá la autorización de la investigación por parte del órgano autonómico competente.

Incluso se prevé que si los resultados parciales obtenidos aconsejan una modificación del proyecto, dicha modificación requerirá un informe favorable del Comité de Ética de la Investigación y habrá de ser comunicada a la autoridad autonómica competente a los efectos oportunos. En todo caso, en el supuesto de proyectos de investigación multicéntricos se garantiza la existencia de un informe único sobre la base de la unidad de criterio.

El art. 16 Ley de Investigación Biomédica tiene su origen en los arts. 7 y 9 del Protocolo adicional sobre Investigación Biomédica que formulan la exigencia de aprobación de toda investigación biomédica por el órgano competente y de sometimiento de la misma al examen independiente de un Comité de Ética.

Por otro lado, el art. 17 relativo a las garantías de control y seguimiento, establece que la investigación deberá ajustarse al contenido del proyecto autorizado, ostentando en todo momento las autoridades sanitarias facultad de inspección, pudiendo tener acceso a las historias clínicas individuales de los sujetos del estudio respecto de las cuales deberán guardar su carácter confidencial. Asimismo, la autoridad autonómica deberá proceder, en los casos en que no se hayan observado los requisitos establecidos legalmente y sea necesario para proteger los derechos de los ciudadanos, a suspender 
cautelarmente -a instancias del Comité de Ética de la Investigación o por iniciativa propia- la investigación autorizada.

Finalmente, el art. 18 culmina el Capítulo II, abordando la materia relativa a las compensaciones por daños y su aseguramiento. En este punto, la Ley de Investigación Biomédica excede con mucho lo previsto en el Protocolo Adicional sobre Investigación Biomédica, que en su art. 31 (Reparación del daño) establece únicamente «la persona que haya sufrido un daño resultante de su participación en una investigación tiene derecho a una reparación equitativa en las condiciones y según las modalidades previstas por la ley».

En este sentido, el art. 18 Ley de Investigación Biomédica sigue a grandes rasgos, en relación con el particular, la regulación prevista en materia de ensayos clínicos con medicamentos: art. 61 (Garantías de asunción de responsabilidades) de la Ley 29/2006, de 26 de julio, de garantías de los medicamentos y productos sanitarios -a la que incluso se remite el art. 18.5 en los demás aspectos no regulados por la Ley de Investigación Biomédica relativos a la responsabilidad por daños y a su aseguramiento-, y art. 8 (Del seguro u otra garantía financiera de los sujetos del ensayo) Real Decreto $223 / 2004$, de 6 de febrero, por el que se regulan los ensayos clínicos con medicamentos.

En este sentido, la realización de una investigación que comporte un procedimiento invasivo en seres humanos exige el aseguramiento previo de los daños y perjuicios que pudieran derivarse para la persona en la que se lleva a efecto (art. 18.2). De esta manera, de producirse un daño se establece la responsabilidad solidaria en caso de que, por cualquier circunstancia, el seguro no cubra enteramente los daños, del promotor, del investigador responsable y del hospital o centro en el que se llevó a cabo, incluso aunque no medie culpa, incumbiéndoles la carga de la prueba. A estos efectos ni la autorización administrativa, ni el informe del Comité de Ética de la Investigación les eximirá de responsabilidad. Para completar el régimen legal reseñado se establece una presunción iuris tantum (que admite prueba en contrario) en virtud de la cual se presume que los daños que afecten a la salud de la persona sujeta a la investigación, durante su realización y en el año siguiente a su terminación, se han producido como consecuencia de la investigación. Pasado dicho plazo es el perjudicado el que debe probar el daño y la relación de causalidad entre la investigación y el daño.

Lo que procede poner de manifiesto es que, un régimen legal tan estricto puede suponer un verdadero obstáculo al desarrollo de la investigación biomédica, máxime cuando se establece una presunción tan amplia como que todo daño aparecido en el periodo de un año desde la finalización de la investigación resulta reconducible a la misma. Sobra decir, que la prueba en contra de lo anterior se convertirá en una verdadera probatio diabolica para el promotor, investigador y hospital o centro. A sabiendas de lo anterior, y tomando en consideración que el Título II Ley de Investigación Biomédica resulta aplicable a las investigaciones que impliquen procedimientos inva- 
sivos en seres humanos distintas a las propias de la esfera del medicamento y el producto sanitario (que quedan sometidas a su legislación sectorial), procedería la adopción de medidas por parte de la iniciativa pública con el fin de fomentar la experimentación en estas áreas. Interés particular ostenta, en este sentido, lo dispuesto en el art. 8 apartado 7 del Real Decreto $223 / 2004$, de 6 de febrero, por el que se regulan los ensayos clínicos con medicamentos en virtud del cual «cuando el promotor e investigador principal sean la misma persona y el ensayo clínico se realice en un centro sanitario dependiente de una Administración pública, ésta podrá adoptar las medidas que considere oportunas para facilitar la garantía de los riesgos específicos derivados del ensayo en los términos señalados en los apartados anteriores, con el objeto de fomentar la investigación». La asunción de una medida de este tipo resultaría particularmente recomendable en la esfera de la experimentación no farmacológica (o de los productos sanitarios), habida cuenta de los menores intereses económicos implicados en la misma, a pesar de lo cual el régimen de responsabilidad legal de los sujetos intervinientes resulta ciertamente importante.

\subsection{Capítulo III. Situaciones específicas.}

El capítulo III del Título II Ley de Investigación Biomédica establece una serie de previsiones específicas en relación con tres supuestos particulares en razón de la situación en la que se encuentran los sujetos: investigaciones durante el embarazo y la lactancia (art. 19), personas que no tengan capacidad para prestar su consentimiento (art. 20) e investigación en personas incapaces para consentir debido a su situación clínica (art. 21).

En relación con estos tres casos, cuya regulación concreta proviene nuevamente del Protocolo Adicional sobre Investigación Biomédica, se pretenden extremar las cautelas respecto de estos grupos de personas, minimizando los riesgos a los que pueden ser sometidos (particularmente si de las referidas investigaciones no se va a derivar un beneficio directo para la salud), y prestando particular importancia a los aspectos relativos al consentimiento (así, en el caso de incapaces, en el que el mismo deberá otorgarse por sus representantes legales o en el de personas incapaces de consentir debido a su situación clínica, en el que deberá respetarse cualquier objeción expresada previamente por el paciente que sea conocida y habrá de informarse al sujeto o a sus representantes legales a la mayor brevedad). No obstante, el Protocolo adicional prevé una situación específica que no ha hallado acogida en la ley española: la de investigaciones que se lleven a cabo en personas privadas de libertad.

Investigaciones durante el embarazo y la lactancia.

El art. 19 Ley de Investigación Biomédica que se ocupa del particular reproduce de manera absolutamente mimética las disposiciones del art. 18 Protocolo Adicional al Convenio sobre Derechos Humanos y Biomedicina, 
relativo a la Investigación Biomédica, con lo que cabría dar por reproducidos los comentarios realizados en relación con el mismo.

A efectos sistemáticos procede poner de manifiesto que el referido precepto de la ley española limita la posibilidad de autorizar una investigación en la que participe una mujer embarazada, respecto de la cual dicha investigación no vaya a producir un beneficio directo, o sobre el embrión, el feto, o el niño después de su nacimiento ${ }^{71}$, a los casos en los que se cumplan las siguientes condiciones:

a) Que la investigación tenga el objeto de contribuir a producir unos resultados que redunden en beneficio de otras mujeres, embriones, fetos o niños.

b) Que no sea posible realizar investigaciones de eficacia comparable en mujeres que no estén embarazadas.

c) Que la investigación entrañe un riesgo y un perjuicio mínimos para la mujer y, en su caso, para el embrión, el feto o el niño. Ello resulta plenamente coherente con lo dispuesto en el art. 14.3 de la propia Ley de Investigación Biomédica.

d) Que la embarazada o los representantes legales del niño, en su caso, presten su consentimiento en los términos legalmente previstos.

Por último, y en relación con investigaciones que se lleven a cabo en una mujer durante el periodo de lactancia, se exige una especial toma en consideración con el fin de evitar un impacto adverso en la salud del niño.

Protección de personas que no tengan capacidad para expresar su consentimiento.

El art. 20 Ley de Investigación Biomédica regula los supuestos de investigaciones sobre menores así como sobre personas incapaces de obrar (salvo que, en función a su grado de discernimiento, la resolución judicial de incapacitación les autorice para prestar su consentimiento a la investigación). Esta materia de nuevo procede del Protocolo Adicional relativo a la Investigación Biomédica, y en concreto, de su art. 15 (protección de personas incapaces de consentir a la investigación) siendo la regulación absolutamente análoga, más allá de concreciones de matiz que se contienen en uno y otro texto.

En este punto, la regulación española distingue oportunamente entre investigación terapéutica y no terapéutica, imponiendo requisitos más estrictos en el segundo caso. En relación con el primer supuesto, es decir, el de aquellas experimentaciones sobre menores o incapaces cuyos resultados

${ }^{71}$ Aun cuando exista dicho beneficio directo, y en virtud del art. 14.2 Ley Investigación Biomédica, la investigación no deberá implicar para el ser humano riesgos y molestias desproporcionados en relación con los beneficios potenciales que se puedan obtener. 
puedan producir beneficios reales o directos para la salud, sólo podrán llevarse a cabo cuando se cumplan las siguientes condiciones:

-Que no se pueda realizar una investigación de eficacia comparable en individuos capaces de otorgar su consentimiento.

-Que la persona que vaya a participar en la investigación haya sido informada por escrito de sus derechos y de los límites prescritos en la Ley y la normativa que la desarrolle para su protección, a menos que esa persona no esté en situación de recibir la información.

-Que los representantes legales de la persona que vaya a participar en la investigación hayan prestado su consentimiento por escrito, después de haber recibido la información legalmente establecida. Los representantes legales tendrán en cuenta los deseos u objeciones previamente expresados por la persona afectada.

Además, en este punto hay que poner de manifiesto la relevancia del art. 14.2 Ley de Investigación Biomédica, que al trazar los principios generales de las experimentaciones que implican procedimientos invasivos en seres humanos impone que la investigación no implique riesgos y molestias desproporcionados en relación con los beneficios potenciales que se puedan obtener, lo cual resultaría plenamente de aplicación en este supuesto.

Por el contrario, en el caso de investigación no terapéutica en este ámbito, la misma podrá ser autorizada de manera excepcional, exigiéndose además de los requisitos pormenorizados supra (salvo el del beneficio directo, que por definición no puede aquí concurrir) los siguientes:

-Que la investigación tenga el objeto de contribuir, a través de mejoras significativas en la comprensión de la enfermedad o condición del individuo, a un resultado beneficioso para otras personas de la misma edad o con la misma enfermedad o condición, en un plazo razonable.

-Que la investigación entrañe un riesgo y una carga mínimos para el individuo participante (de nuevo, coherentemente con el art. 14.3 Ley de Investigación Biomédica).

-Que la autorización de la investigación se ponga en conocimiento del Ministerio Fiscal.

Investigación en personas incapaces de consentir debido a su situación clínica.

La previsión del art. 21 Ley de Investigación Biomédica se dirige a permitir, bajo determinadas condiciones ciertamente estrictas, la realización de experimentaciones que impliquen procedimientos invasivos en seres humanos en situaciones de emergencia clínica. En este contexto, y de acuerdo con la propia ley, se consideran investigaciones en situaciones de emergencia aquéllas en las que la persona no se encuentre en condiciones de otorgar su consentimiento y, a causa de su estado y de la urgencia de la situación, sea imposible obtener a tiempo la autorización de los representantes legales del paciente o, de carecer de ellos, de las personas que convivieran con aquél. 
En todo caso, el inicio de la investigación en situación clínica de emergencia no obsta para que la persona que participe en la misma o, en su caso, sus representantes legales, hayan de ser informados a la mayor brevedad posible. Asimismo, debe solicitarse el consentimiento para continuar participando en las investigaciones, en cuanto el paciente se halle en condiciones de prestarlo.

Podrían sistematizarse los requisitos para llevar a cabo investigación en personas incapaces de consentir debido a su situación clínica en torno a los siguientes puntos:

-Que no sea posible realizar investigaciones de eficacia comparable en personas que no se encuentren en esa situación de emergencia.

-Que en el caso de que no sea previsible que la investigación vaya a producir resultados beneficiosos para la salud del paciente, tenga el propósito de contribuir a mejorar de forma significativa la comprensión de la enfermedad o condición del paciente, con el objetivo de beneficiar a otras personas con la misma enfermedad o condición, siempre que conlleve el mínimo riesgo e incomodidad para aquél.

-Que la autorización de la investigación se ponga en conocimiento del Ministerio Fiscal.

-Por otro lado, habrá de respetarse cualquier objeción expresada previamente por el paciente que sea conocida por el médico responsable de su asistencia, por el investigador o por el Comité de Ética de la Investigación.

\subsection{Capítulo IV. Seguridad y supervisión.}

A lo largo de los artículos 22 a 25 de la Ley de Investigación Biomédica se establecen una serie de previsiones destinadas a velar por la seguridad de la investigación y la salud del paciente en cualquier momento del procedimiento. De nuevo la regulación establecida en la Ley de Investigación Biomédica sigue a grandes rasgos lo dispuesto en los artículos 21 a 24 Protocolo Adicional al Convenio de Derechos Humanos y Biomedicina relativo a la Investigación Biomédica. En este sentido, el art. 22 establece los criterios de prevención de riesgos, exigiendo la adopción de las medidas necesarias para garantizar la seguridad de la investigación y reducir los riesgos y las incomodidades para los participantes, así como la necesidad por parte del investigador responsable de acreditar que, tanto él como su equipo de investigación, se encuentran en posesión de la cualificación y experiencias adecuadas al ámbito de la investigación propuesta. Ello resulta de todo punto lógico, si tomamos en consideración la responsabilidad profesional asumida al llevar a cabo un proyecto de investigación que implica la práctica de procedimientos invasivos en seres humanos.

En relación con la evaluación del estado de salud de las personas participantes en la investigación se traslada al sujeto del ensayo el deber de facilitar los datos reales sobre su estado físico o de salud, habiendo, no obstante, el investigador de tomar las medidas necesarias, que incluirán, en su caso, la 
consulta a los médicos responsables de la asistencia de los participantes, para comprobar dicho extremo previamente al inicio de la investigación, al objeto de que los sujetos para los que la investigación revista especial riesgo queden excluidos de la misma (art. 23). Resulta procedente poner de manifiesto que el Protocolo adicional sobre investigación biomédica en ningún apartado establece la referida obligación por parte del sujeto de la investigación de comunicar los datos sobre su estado físico o de salud, aspecto incorporado de manera novedosa por la Ley de Investigación Biomédica. Finalmente, se hace referencia al caso en el que la investigación implique a mujeres en edad fértil, habiendo de tenerse en cuenta el posible impacto adverso sobre un embarazo existente desconocido o posterior, así como sobre la salud del embrión, el feto o el niño.

El art. 24 Ley de Investigación Biomédica garantiza que la investigación no retrasará o privará a los participantes de los procedimientos médicos preventivos, diagnósticos o terapéuticos que sean necesarios para su estado de salud. En el caso de investigaciones asociadas con la prevención, diagnóstico o tratamiento de enfermedades, deberá asegurarse que los participantes que se asignen a los grupos de control reciban procedimientos probados de prevención, diagnóstico o tratamiento. En este sentido, el investigador hará constar los extremos anteriores en el protocolo del ensayo que vaya a someter a evaluación y autorización. Asimismo, únicamente podrá recurrirse al uso de placebo si no existen métodos de eficacia probada, o cuando la retirada de estos métodos no presente un riesgo o perjuicio inaceptable para el paciente.

Finalmente, el art. 25 establece la posibilidad que asiste en todo momento al Comité de Ética de la Investigación para adoptar las medidas oportunas con el fin de comprobar que la continuidad del proyecto está justificada a la luz de los nuevos conocimientos que se alcancen a lo largo de su ejecución. Estas evidencias novedosas pueden derivarse del propio proyecto emprendido (así, obtención de determinados resultados parciales que ponen de manifiesto la extremada peligrosidad de la técnica objeto de experimentación) o bien de otros proyectos conocidos por parte de los investigadores implicados (por ejemplo, publicación de resultados de otros estudios en revistas científicas). La Ley de Investigación Biomédica asigna la función de comprobación acerca de la oportunidad de continuar con el proyecto al Comité de Ética de la Investigación, aspecto que queda abierto en función del Protocolo Adicional al Convenio de Derechos Humanos y Biomedicina relativo a la Investigación Biomédica, que no especifica quién haya de desempeñar dicha función. En este sentido, se impone por ley al investigador principal la obligación de remitir de manera inmediata cualquier información relevante para la seguridad de los sujetos participantes. Las finalidades de la comprobación referida por parte del Comité de Ética de la Investigación serán las siguientes: 
-Si es necesario interrumpir la investigación o realizar cambios en el proyecto para que pueda continuar.

-Si los participantes en la investigación o, en su caso, sus representantes, deben ser informados sobre los acontecimientos que puedan ocurrir.

-Si es preciso contar con un consentimiento adicional de los participantes.

En cualquier caso, si como consecuencia de dicha labor fiscalizadora o por cualquier otra circunstancia, resultase necesaria la modificación de las condiciones autorizadas, ésta exigiría el dictamen favorable del Comité de Ética de la Investigación y la aprobación de la autoridad correspondiente. Dicho precepto supone la positivización y el consiguiente otorgamiento de rango legal a una serie de criterios ya aceptados unánimemente en la comunidad científica ${ }^{72}$ : por un lado, que las investigaciones deben llevarse a cabo en todo caso conforme al protocolo aprobado por el Comité de Ética de la Investigación y, por otro, que toda modificación ulterior del mencionado protocolo debe ser objeto de aprobación por parte de aquel.

De acuerdo con lo dispuesto legalmente, cualquier información relevante sobre la participación en la investigación será comunicada por escrito a los participantes o, en su caso, a sus representantes, a la mayor brevedad. En relación con el particular, el Comité de Ética de la Investigación procederá al seguimiento del cumplimiento de la obligación referida, debiendo dar cuenta de las incidencias que observe a la autoridad competente que dio la autorización para dicha investigación, con el fin de que ésta pueda adoptar las medidas que correspondan, de acuerdo con el artículo 17 de la Ley de Investigación Biomédica y con pleno respeto a lo establecido en la normativa vigente en materia de protección de datos de carácter personal.

El último apartado del art. 25 Ley de Investigación Biomédica ostenta particular interés pues dispone que el investigador responsable informará al Comité de Ética de la Investigación y a la autoridad competente que dio su conformidad a la investigación de las razones por las que decida terminar prematuramente cualquier proyecto de investigación. Con ello, se quieren evitar finalizaciones prematuras de una determinada experimentación basadas no en razones de pertinencia científica o justificadas por la seguridad de los participantes, sino por ejemplo, en criterios meramente comerciales. De esta forma, se pretende impedir que la finalización anticipada se funde meramente en la voluntad de no hacer públicos determinados resultados negativos que, de lo contrario, habrían de ser publicados. Como causa justificada de finalización antes de tiempo cabría citar la obtención de resultados

72 Véase DAL-RÉ, R., «La protección de los sujetos participantes en los ensayos clínicos: supervisión de la conducción del ensayo clínico por el Comité Ético de Investigación Clínica», cit., p. 18. No obstante, acepta dicho autor que, con relativa frecuencia, los investigadores modifican el protocolo inicialmente aprobado, sin informar de nuevo, ni por supuesto, solicitar la oportuna autorización del Comité de Ética correspondiente. 
estadísticos que evidencian que la técnica/tratamiento experimental es significativamente peor que el estándar existente, por lo que sería éticamente inaceptable la continuación del proyecto de investigación. Otro ejemplo sería la publicación de resultados de estudios por otros investigadores que o bien negasen la justificación originaria para la investigación emprendida, o bien pusiesen en cuestión la seguridad de la experimentación ${ }^{73}$.

El art. 25 Ley de Investigación Biomédica implica el desarrollo de una actividad proactiva por parte de los Comités de Ética de la Investigación en el cumplimiento de la labor fiscalizadora que les compete. Básicamente cabe considerar dos formas de materialización práctica de la misma: o bien exigir a los investigadores un detallado proceso de monitorización, o bien configurar un sistema por el cual el personal de la institución donde se realiza el ensayo clínico procede a monitorizarlo o a auditarlo (unidades de esta naturaleza ya existen en determinados hospitales españoles) ${ }^{74}$.

\subsection{Capítulo V. Gestión de la información.}

Los arts. 26 y 27 Ley de Investigación Biomédica tienen su origen igualmente en el Protocolo adicional al Convenio sobre Derechos Humanos y Biomedicina relativo a la investigación biomédica (arts. 27 y 28). En virtud del primer precepto citado (art. 26), se garantiza que si la investigación da lugar a información relevante para la salud de los participantes, ésta deberá ser puesta a su disposición, en el marco de la asistencia en curso o prestando un asesoramiento específico (cuando ello resulte necesario atendiendo a la naturaleza de los resultados y a las opciones disponibles para los participantes). Dicha información puede consistir en las conclusiones de la investigación o en información incidental obtenida durante la experimentación, debiéndose evaluar por parte del investigador su relevancia para la salud o calidad de vida actual o futura de los participantes ${ }^{75}$. En todo caso, debe respetarse escrupulosamente tanto el derecho del sujeto a saber como a no saber (consagrado como principio general en el art. 4.5 Ley de Investigación Biomédica al que remite el art. 26 de la misma norma), con los límites

${ }^{73}$ Ejemplos citados en el Informe Explicativo al Protocolo adicional sobre Investigación Biomédica. Véase Council Of Europe, Additional Protocol to the Convention on Human Rights and Biomedicine concerning Biomedical Research. Explanatory Report, [en línea], 2005 [citado el 1 de octubre de 2011], apartados 126 y s., disponible en Internet: [http://conventions.coe.int/Treaty/EN/Reports/Html/195.htm]

${ }^{74}$ Véase DAL-RÉ, R., «La protección de los sujetos participantes en los ensayos clínicos: supervisión de la conducción del ensayo clínico por el Comité Ético de Investigación Clínica», cit., p. 19.

${ }^{75}$ En este sentido, véase Council Of Europe, Additional Protocol to the Convention on Human Rights and Biomedicine concerning Biomedical Research. Explanatory Report, [en línea], 2005 [citado el 1 de octubre de 2011], apartado 131, disponible en Internet: [http://conventions.coe.int/Treaty/EN/Reports/Html/195.htm] 
doctrinalmente consagrados (así, en el caso del derecho a no saber, cuando dicha información, según criterio del médico responsable, sea necesaria para evitar un grave perjuicio para la salud del sujeto o la de sus familiares biológicos, se informará a un familiar próximo o a un representante, previa consulta del comité asistencial si lo hubiera, debiendo limitarse la comunicación exclusivamente a los datos necesarios para estas finalidades).

Por último, en virtud del art. 27 Ley de Investigación Biomédica el investigador responsable se obliga a remitir - una vez concluida la investigación-un resumen de la misma a la autoridad que dio la autorización y al Comité de Ética de la Investigación. Asimismo, y de solicitarlo, los resultados deben ser comunicados a los participantes. Finalmente, los investigadores deben hacer públicos los resultados de la investigación una vez concluidas atendiendo a los requisitos relativos a los datos de carácter personal y sin menoscabo de los correspondientes derechos de propiedad intelectual e industrial que se pudieran derivar de la investigación.

La cuestión de la publicación de los resultados ostenta una importancia particular ${ }^{76}$, puesto que constituye uno de los mecanismos básicos de control (de naturaleza ex post) de las investigaciones llevadas a cabo ${ }^{77}$. Asimismo, garantizando la publicación se evita la innecesaria duplicación -no sólo en la esfera local, sino igualmente nacional e internacional, dada la difusión presente de conocimientos a través de Internet- de experimentaciones invasivas que, precisamente por utilizar como participantes a seres humanos, deben reducirse al mínimo necesario ${ }^{78}$. Igualmente, se trata de proscribir

${ }^{76}$ En la esfera de los ensayos clínicos con medicamentos GonZÁlez-Torre pone de manifiesto que la publicación constituye una de las grandes necesidades de las empresas farmacéuticas, agrupadas en las llamadas «cinco pes»: pacientes, prestigio, patentes, personal y publicaciones. Véase GonzÁlez-Torre, A. P., Bioética y experimentación con seres humanos, cit., p. 144.

77 DAL-RÉ pone de manifiesto la función de los antiguos Comités Éticos de Investigación Clínica (CEIC) en la comprobación regular de la publicación de los resultados de la investigación. Propone para ello realizar dicha función de manera selectiva, mediante una selección al azar de los estudios a auditar. Otra posibilidad sugerida por dicho autor consistiría en que fueran los propios CEIC los que requiriesen a los investigadores para que les informasen sobre la publicación de los resultados. No obstante, también se evidencia la existencia de ensayos clínicos (EC) que por su propia naturaleza, resultan de más fácil publicación que otros, por su mayor trascendencia para la comunidad médica. Véase DAL-RÉ, R., «La protección de los sujetos participantes en los ensayos clínicos: supervisión de la conducción del ensayo clínico por el Comité Ético de Investigación Clínica», cit., p. 16.

${ }^{78}$ Por otro lado, una de las cuestiones que se plantea en la actualidad es la de la prepublicación de los datos (sobre todo en investigaciones que implican la creación de amplias bases de datos) pues pueden ser de utilidad inmediata para otros investigadores en dicho campo generando así importantes beneficios sociales. Ello, que surge en la esfera del Proyecto Genoma Humano, se ha ampliado a otras esferas de la Biología y la 
mediante la ausencia de publicación la supresión de resultados negativos o positivos por razones comerciales u otras no científicas. Por otro lado, este aspecto entronca directamente con la cuestión del acceso a los resultados de los ensayos clínicos llevados a cabo por parte del público en general, y en particular, por determinados grupos de presión, entre los que destacan particularmente los pacientes, que son quienes ostentan un interés directo en los referidos procesos. En el marco de nuestras sociedades post-industriales en la era de la biotecnología cuestiones como las vinculadas con nuevas posibilidades diagnósticas o terapéuticas se enmarcan en el proceso de «democratización de la tecnología», aspectos en relación con los cuales el gran público desea tener un conocimiento de los avances producidos y participar activamente en la toma de decisiones ${ }^{79}$. Ello no implica aún una difusión importante de noticias de ámbito médico-científico en los medios de comunicación social más extendidos en España ${ }^{80}$, pero sí que ha dado lugar a un interés creciente por estos temas.

Procede aceptar, no obstante, que la publicación de los resultados de un ensayo clínico se encuentra condicionada por diferentes variables, entre las que se encuentran cuestiones tales como las propias evidencias alcanzadas (es notorio que resulta significativamente más sencillo publicar ensayos cuyos resultados son positivos que aquellos que no llegan a confirmar las hipótesis de partida), el tamaño del estudio, etc. Suficientemente conocidos resultan factores tales como el «sesgo de publicación» ${ }^{81}$, puesto de manifiesto

Medicina. En relación con el particular y la problemática que ello puede plantear, véase OPINION, «Prepublication data sharing», Nature, 461, pp. 168 y ss. [en línea], 2011 [citado el 1 de octubre de 2011], disponible en Internet: [http://www.nature.com/nature/journal/ v461/n7261/full/461168a.html]

79 Acerca de la incidencia de los grupos de presión en los procesos vinculados con los ensayos clínicos, véase Avendaño SolÀ, C., «Ensayos clínicos y grupos de presión», en CARné, X. / Costa, J. et al., Problemas y controversias en torno al ensayo clínico, cit., pp. 25 y ss.

${ }^{80}$ En 1996 las noticias de ámbito médico-científico en los 6 periódicos de mayor venta en España se situaban en 1.273, de las que solo un 1\% (15) se referían específicamente a temas relacionados con ensayos clínicos. No obstante, el acceso de la población en general a dicha información experta ha conocido un auge espectacular en los últimos años a raíz del fenómeno internet. Véase Vilarroya, O., «El ensayo clínico en la democratización de la información experta», en CARnÉ, X. / Costa, J. et al., Problemas y controversias en torno al ensayo clínico, cit., pp. 71 y ss.

81 Véase Andrés-Trelles, F. de, «Difusión selectiva de los ensayos clínicos. Lo que conoce la industria, lo que conoce el prescriptor», en CARnÉ, X. / Costa, J. et al., Problemas y controversias en torno al ensayo clínico, cit., p. 77. Según GonzÁlez-Torre, un efecto negativo de este proceso en virtud del cual se tienden a publicar con más facilidad las investigaciones con resultados positivos es que los estudios sistemáticos sobre artículos de revistas especializadas dan lugar a conclusiones equivocadas sobre la efectividad de los tratamientos, sobrevalorándolos, de manera que se puede llegar a exponer a los 
de manera repetida, consistente en la no publicación de resultados negativos y que, en gran parte puede relacionarse con el hecho de que la naturaleza atractiva de los resultados puede primar en el interés editorial sobre la calidad del método con el que se han conseguido. Un paso fundamental al objeto de lograr que la gran mayoría de los ensayos clínicos se hagan públicos es la iniciativa que se ha dado a conocer como «amnistía de los ensayos clínicos», en la que los editores y otros responsables académicos se han comprometido a facilitar la publicación de todos aquellos ensayos clínicos que por irrelevancia, conflicto de intereses u otro tipo de impedimentos técnicos no han visto la luz en forma de publicación ${ }^{82}$. Dicha iniciativa sólo ha resultado posible en el marco de internet. En este punto, procede citar la importancia de la llamada Colaboración Cochrane, que como pone de manifiesto Bonfill $^{83}$, constituye una organización internacional dirigida a promover la producción, actualización y divulgación de revisiones sistemáticas sobre los efectos de los tratamientos o de las intervenciones sanitarias. De acuerdo con dicho autor, la referida iniciativa se encuentra organizada por grupos colaboradores de revisión establecidos en virtud de problemas de salud. De esta manera se trata de identificar todos los ensayos clínicos realizados en cualquier idioma y en cualquier país con el fin de registrarlos en una base de datos central, de importancia significativa para conocer ensayos clínicos en cada área de actividad.

Con ello queda cerrado el ciclo relativo a la práctica de las investigaciones que implican procedimientos invasivos en seres humanos. Cuestiones posteriores, que por razones ligadas al propio propósito de la presente contribución deben quedar fuera de nuestro análisis, son las relacionadas con la ulterior aplicación de los resultados de las experimentaciones a la práctica asistencial en forma normalmente de nuevas posibilidades diagnósticas o terapéuticas ${ }^{84}$.

pacientes a terapias inútiles e incluso peligrosas. Véase GonzÁlez-Torre, A. P., Bioética y experimentación con seres humanos, cit., p. 146.

${ }^{82}$ Así lo pone de manifiesto VILARroya, O., «El ensayo clínico en la democratización de la información experta», en CARné, X. / Costa, J. et al., Problemas y controversias en torno al ensayo clínico, cit., p. 73.

${ }^{83}$ Véase BonfiLl, X., «Situación actual de los ensayos clínicos no farmacológicos en España», cit., pp. 13 y s. En el marco de dicha iniciativa ostentan particular importancia la Cochrane Library, revista electrónica donde se divulgan las revisiones de la Colaboración Cochrane y el registro Central.

${ }^{84}$ Ello nos enfrenta con problemas éticos diversos que merecen un análisis pormenorizado. Para una profundización sobre el particular véase Permanyer Miralda, G., «La aplicación de los ensayos clínicos a la práctica asistencial», en CARNÉ, X. / CosTA, J. et al., Problemas y controversias en torno al ensayo clínico, cit., pp. 47 y ss. 
TITLE: Reflections on the legal framework on invasive procedures research involving human beings in Spain.

RESUMEN: La entrada en vigor de la Ley 14/2007, de 3 de julio, de Investigación Biomédica supuso la consagración, por primera vez en España, de un marco normativo exhaustivo y carente de lagunas legales en esta esfera. El presente trabajo analiza la legislación aplicable en materia de investigaciones que implican procedimientos invasivos en seres humanos reguladas en el Título II de la referida ley, quedando, no obstante, excluidos de dicho ámbito los ensayos clínicos en la esfera del medicamento, objeto de regulación en virtud de la Ley 29/2006, de 26 de julio, de garantías y uso racional de los medicamentos y los productos sanitarios.

PALABRAS CLAVE: investigaciones que implican procedimientos invasivos en seres humanos, ensayos clínicos, investigación biomédica.

ABSTRACT: The entry into force of the Spanish Law 14/2007 of 3rd July, on Biomedical Research implied the establishment for the first time of a complete legal framework in this field. This paper analyzes the legislation applicable to the experimentation with human beings regulated in Title II of the mentioned law, excepting clinical essays in the field of medicaments, regulated by Law 29/2006 of 26th July, on surety and rational use of medicaments and sanitary products.

KEY WORDS: research implying invasive procedures in human beings, clinical essays, biomedical research.

Recibido: 23.04.2012

Aceptado: 31.05.2012 